Portland State University

PDXScholar

3-29-1992

\title{
Working It Out: ESL Literacy Skills, Strategies, and Systems in the Workplace
}

Mary Louise Cohn

Portland State University

Follow this and additional works at: https://pdxscholar.library.pdx.edu/open_access_etds

Part of the Bilingual, Multilingual, and Multicultural Education Commons Let us know how access to this document benefits you.

\section{Recommended Citation}

Cohn, Mary Louise, "Working It Out: ESL Literacy Skills, Strategies, and Systems in the Workplace" (1992). Dissertations and Theses. Paper 4579.

https://doi.org/10.15760/etd.6463

This Thesis is brought to you for free and open access. It has been accepted for inclusion in Dissertations and Theses by an authorized administrator of PDXScholar. Please contact us if we can make this document more accessible: pdxscholar@pdx.edu. 
AN ABSTRACT OF THE THESIS OF Mary Louise Cohn for the Master of Arts in Teaching English to Speakers of Other Languages presented March 29, 1992

Title: Working It Out: ESL Literacy Skills, Strategies, and Systems in the Workplace.

APPROVED BY THE MEMBERS OF THE THESIS COMMITTEE:

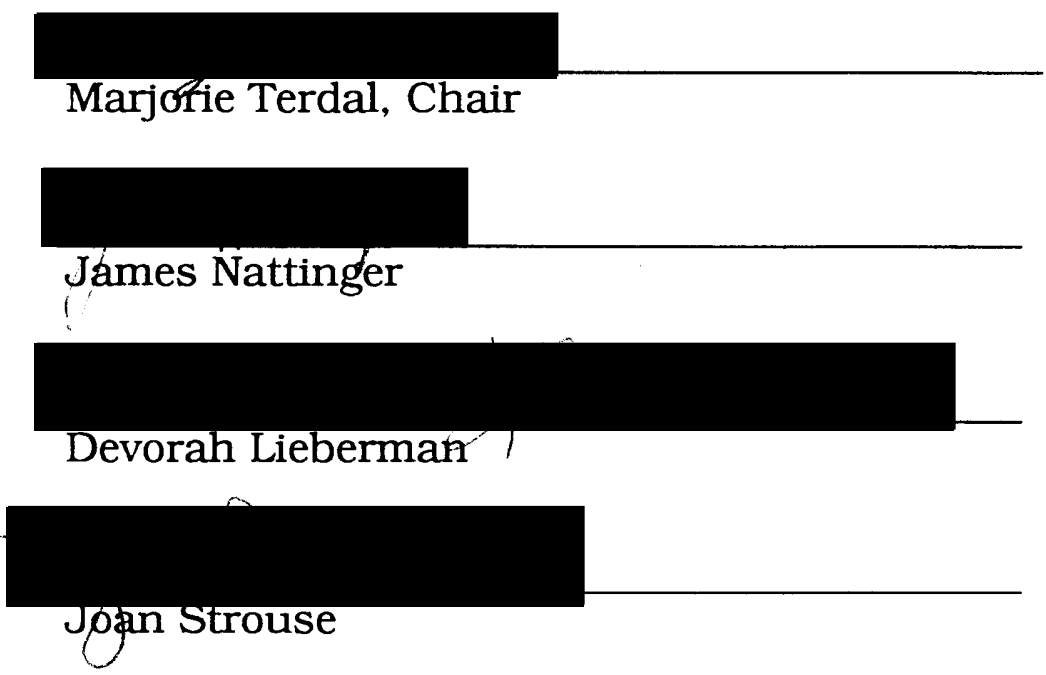

This study investigates the strategies and resources a group of non-native English speakers with limited reading ability use to fulfill literacy functions as work. The nineteen study subjects are employed as production workers in a large electronics manufacturing company. Using in-depth interview data, limited testing and document analysis, the study addresses three major research questions: 1) For what functions are reading and writing actually used in the workplace? What level of 
reading and writing do these functions assume? 2) How do these literacy functions relate to the rest of the work system? 3) How do limited readers fulfill these literacy functions? What kinds of individual literacy skills, social networks and alternative approaches do they use? How can findings be applied to workplace, ESL, job training, and employee communications?

The findings show that the primary function of literacy in this workplace is to maintain process quality and flow. Secondary functions include maintenance of the social organization and the use of literacy for learning the job or learning English. The study finds that limited readers can accomplish literacy functions even if they cannot read documents connected to the function. They use extensive social networks as one strategy for accomplishing literacy fuctions. They also use job aids, watch processes being performed, or memorize processes. English verbal skills are necessary for many alternative strategies. The study illustrates systemic relationships among work process design, individual literacy skill, and alternative literacy strategies such as using help networks. The study also finds that participants take ESL class as a means to advance as well as to succeed on the current job.

The study suggests that employers support ESL instruction as a long-term skill-improvement strategy, but look at redesigning work systems, job training, and employee communications to solve immediate performance problems with limited readers. The study recommends that workplace ESL instructors balance student and employee needs by using workplace materials as one part of a wider curriculum; it also suggests that ESL instructors may have an important role to play in the workplace 
by acting as performance consultants, going beyond the classroom to recommend changes in the entire work system as they affect English and literacy learning.

Because of the small sample size, more research is needed. 


\title{
WORKING IT OUT: ESL LITERACY SKILLS, STRATEGIES, AND SYSTEMS IN THE WORKPLACE
}

\author{
by \\ MARY LOUISE COHN
}

A thesis submitted in partial fulfillment of the requirements for the degree of

\author{
MASTER OF ARTS \\ in \\ TEACHING ENGLISH TO \\ SPEAKERS OF OTHER LANGUAGES
}


TO THE OFFICE OF GRADUATE STUDIES:

The members of the Committee approve the thesis of Mary Louise Cohn presented March 29, 1993

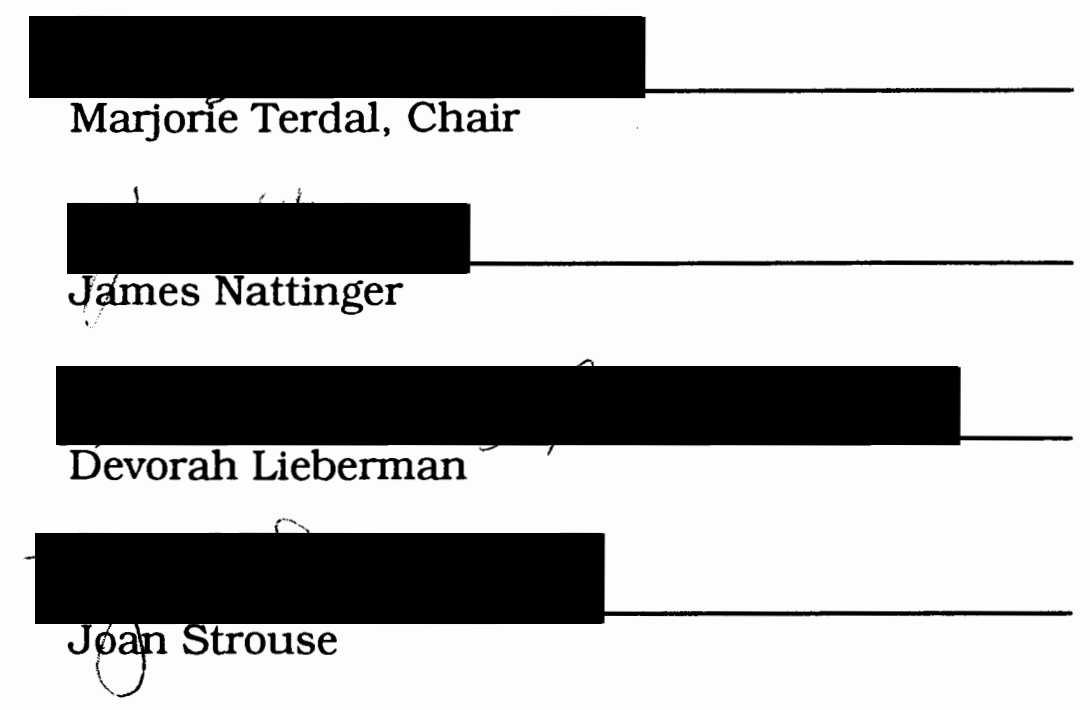

\section{APPROVED:}

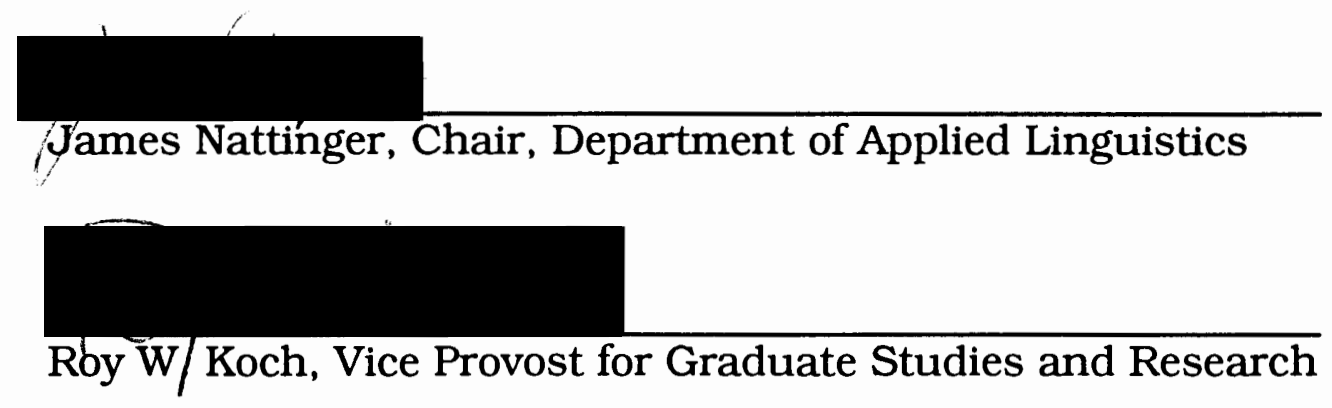


TABLE OF CONTENTS

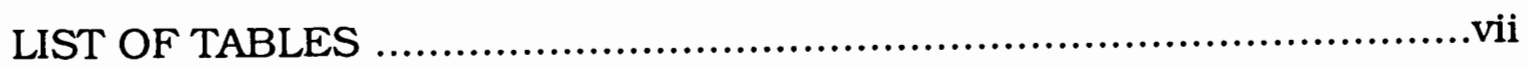

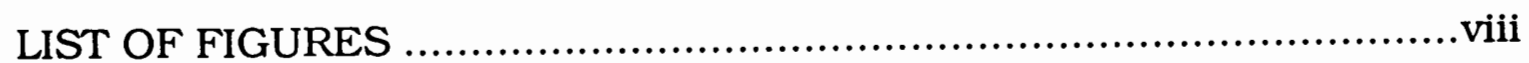

\section{CHAPTER}

I INTRODUCTION...................................................... I

Research Questions ............................................... 4

Definition of Terms …............................................ 7

II LITERATURE REVIEW ................................................ 9

Defining Literacy ................................................. 9

Functional Literacy

Literacy Education as a Business Issue ................... 14

Growing Awareness of the "Literacy Problem" Growth in Workplace Literacy Programs

Theory to Practice: The Influence of Functional Literacy on Workplace Literacy Programs................. 17

Differences in School and Work Literacy Literacy Task Analysis

Moving Ahead: New Perspectives on Functional Literacy and the Workplace ................................... 21

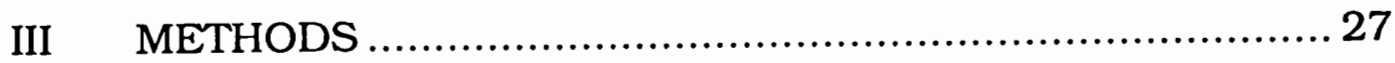

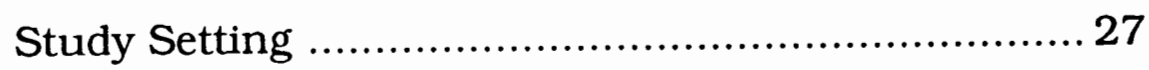

Tri-X Company

The Workplace English Classes 
Study Participants 30

How Participants Were Chosen

Participant Demographics

Data Collection

Participant Interviews

The B.E.S.T. Test

Document Analysis

IV MAKING IT WORK: PARTICIPANT VIGNETTES

Introduction

Vignette 1: May 40

Vignette 2: Haing 42

Vignette 3: Yung. 44

Vignette 4: Vinh 47

Vignette 5: Song 48

Vignette 6: Sook 51

V RESULTS

Interview Results 55

"Satisfy Customers:" How Participants Talk About Work

Verbal Interaction on the Job

Functions of Reading and Writing at Work

Facing New Challenges: Learning the Job

Alternative Strategies for Accomplishing

Literacy Functions

Extended Networks: Literacy at Home

B.E.S.T. Test Results

Unexpected Results

Test Results 
Results of Document Analysis 85

Process Specifications

Tri-X Weekly News

Benefits Workbook

Letters from Management

VI DISCUSSION

Question One: Functions of Literacy in the

Workplace

Process Documentation

Organization Communication

Literacy to Learn English on the Job

Question Two: How Literacy Functions Relate to the Work System 95

Literacy Processes, Work Process Design, and Quality

Organization Communication and Marginalization

Question Three: How Limited Readers Fulfill Literacy Functions 100

Individual Reading and Writing Skills and Strategies Applied to the Literacy Function Relationship and Social Networks Used to Fulfill Literacy Functions

Other Alternatives: Bypassing Literacy The Literacy System

Study Limitations 103

Limitations of Research in the Workplace

VII RECOMMENDATIONS 107

Recommendations for Employers 107

Work Process Design

Process Documentation

Job Training

Supporting ESL and Literacy Training

Employee Communications 
Recommendations for Workplace

ESL Instruction ................................... 112

The Place of Job Task Analysis and

Functional-Context Curricula

Balancing Student and Employer Needs

Hands-On Classroom Approach Suggested

by Study Findings

Rethinking the Role of the Workplace ESL Instructor

Afterword: Russell Revisited

REFERENCES

APPENDICES

A CONSENT FORM ................................................. 123

B INTERVIEW GUIDE........................................... 126

C SAMPLE TRANSCRIPT .......................................... 128

D FRY READABILITY SCALE GUIDELINES ..................... 138 


\section{LIST OF TABLES}

TABLE

PAGE

I Demographic Summary .................................... 33

II Literacy Functions and Materials ............................61

III B.E.S.T. Test Scores, Student Performance Levels (SPL),

Years Previous Education ..............................8 82

IV Selected Document Readability Based on Fry Scale .........87 


\section{LIST OF FIGURES}

FIGURE

PAGE

1. Learning Map for Manufacturing Process ....................97 


\section{CHAPTER I}

\section{INTRODUCTION}

In the past decade, the U.S. business and popular press has devoted much attention to the basic skills and literacy problem in the U.S. workplace. In the late 1980s, articles appeared in every major business magazine about demographic trends showing that new entrants into the workforce in the year 2000 will be made up of a larger percentage of minority groups, women, and immigrants than ever before. They portrayed a decaying educational system and warned that without serious intervention, the basic skill levels of the workforce in the United States would not keep up with the projected need for skills to compete in the global economy. Literacy had become not just a social problem of some distant underprivileged nation, but an economic issue that could affect anyone. In response, U.S. industry, which has historically provided many kinds of job-specific training from bank teller to auto assembler to silicon crystal-grower, has begun to provide training in "basic skills" such as literacy, math, and English as a Second Language (ESL).

Businesses have started to sponsor basic skills training, including ESL, for employees in the workplace because they find generic-skill programs such as those offered by community colleges less effective than workplace-specific programs. These workplace programs tend to view the workplace literacy deficit as a problem that can be solved by improving 
individual skill levels, and therefore focus training on building individual skills in reading and writing. The popularity of job task analysis, a curriculum-building technique that looks at the skills individuals need to accomplish discrete job tasks, has reinforced the notion that building individual reading and writing skills is the best way to build functional literacy in the workplace.

In spite of alarms sounded by the press about the dire state of worker literacy, every day thousands of individual workers who cannot read even at high school levels do in fact perform their jobs very well. Many of these people are non-native English speakers with technically challenging jobs. How do they succeed? And why do they sometimes-unpredictably--fail? These are questions that business managers are asking.

Imagine the following scenario; "Russell" could be any one of a number of company managers who approach their training department for help:

Russell, a manufacturing manager in a high-technology firm, observes that some Asian workers who have just transferred into his area are making errors in their work. Although he initially assumes that their problem is caused by lack of English comprehension, he asks them what the problem is; they respond that they have no problem, that they just need time to learn. Russell talks to the workers' previous manager and learns that all have impeccable productivity and quality records. Their previous manager admits, however, that they were sometimes "hard to understand." After talking to other workers in the group, the manager 
concludes that the reason for errors is that the new workers cannot read the process specification changes he just gave them. The manager is puzzled--after so many years of success in a similar job, why are these people having problems now? Haven't they had to read before? Russell approaches the training department and asks for advice: Should he send the workers to ESL class to learn to read? Should he begin testing all his workers before he hires them? What should he do?

In fact, this scenario is not entirely imaginary. Just such a manager approached me with a similar dilemma: he was sure he had a "literacy problem," and also conjectured that he might have an "English problem." But because he had not seen rapid individual skill improvements from previous ESL or literacy programs, the manager was not sure that training could solve his problem. He was considering testing all employees for basic literacy skills, but testing involved touchy legal and ethical issues since some other Asian workers did not read much, but had no performance problems. Besides, testing would not solve his current problem. He was looking for real answers on how to improve performance and maintain it at a high level. At the time, I was working at Tri-X Company as a manager of the education and training department.

In a sense, this study is an attempt to find some answers for managers like Russell. It is time to look beyond the traditional solutions of classes or pre-employment testing when lack of literacy or English skills seems to be causing a performance problem. Russell's ESL workers--and others who he will never know cannot read--have shown 
that they can learn to function in a work environment that assumes literacy, even if they do not possess those literacy skills themselves. Ethnographic research into literacy communities (e.g. Gowan, 1990; Heath, 1986; Reder, 1987) suggests that people regularly use extensive networks and reciprocal social interactions to fulfill individual literacy tasks. The age-old literacy specialist, the village scribe, is a classic solution some societies have adapted to accomplish literacy functions for the group. Perhaps modern work groups create literacy specialists, just as they have quality control experts or machine repair specialists. Perhaps people find ways together to accomplish functions that are normally assumed to require literacy without using reading or writing skills at all. Clearly, to find out how people succeed in a literate workplace, it is necessary to look beyond the individual skill level. Investigation should begin with how employees work together, how they organize literacy job tasks among themselves, and how they utilize networks and relationships. By addressing these questions, it is possible that the notion of functional literacy in the workplace may be expanded to cover a system of skills and functions, rather than just an individual skill set. This kind of research may also suggest new approaches to use in workplace literacy training programs, and in job training programs.

\section{RESEARCH QUESTIONS}

This study investigates the strategies and resources a group of non-native English speakers with limited reading ability, employed as production workers in a high-tech firm, use to fulfill literacy functions at 
work. Like many other limited readers, the nineteen study subjects have been able to maintain long and productive employment during harsh economic times, even when many of their co-workers have been laid off. How have they succeeded? Job task analyses may provide details about what workers are called upon to do with literacy, but they do not yield satisfactory answers about how some very limited readers learn new jobs and achieve quality results day after day without high proficiency in reading and writing. In the present study, the lens of inquiry is widened to encompass not only an individual's job task and individual skills applied to that task, but the relationship of that task and those skills to the group output, and the entire bank of resources available in the workplace and beyond. By investigating the following research questions, the study seeks to shed further light on the full range of resources, relationships, and skills non-native English speakers with limited reading skills bring to bear in the world of work:

1. For what functions are reading and writing actually used in the workplace? What level of reading and writing do these functions assume?

2. How do these literacy functions relate to the rest of the work system? For example, to what extent are these functions related to individual job performance, success of the group, and success of the organization?

3. How do limited readers--or the group as a whole--fulfill these literacy functions? Specifically, 
a. What kinds of individual reading or writing skills and strategies or techniques do they apply to the literacy function?

b. What kinds of relationships or social networks, if any, do limited readers make use of to fulfill literacy functions?

c. Do work teams "share" or specialize in literacy functions? If so, how?

d. If individuals or groups do not use their own literacy skills to fulfill literacy functions, what alternative approaches do they apply?

e. How can we leverage what we discover about the strategies limited readers use in the workplace to enhance workplace ESL, job training, and employee communications programs?

In order to answer these questions, this study conducted and analyzed in-depth interviews with nineteen ESL workers attending a Workplace ESL class at Tri-X company, tested their literacy skills, and analyzed typical literacy documents encountered in the workplace. Using these methods, the study was able to draw a broad scenario of the literacy landscape ESL workers inhabit, and their role in that picture.

The following chapter summarizes research on literacy and the workplace; Chapter III details the study setting, participant demographics, and data-gathering methods. In Chapter IV, vignettes of study participants show literacy and work in the real lives of six people. Chapter V describes results of interviews, tests, and document analyses. 
In Chapters VI and VII, study questions are further analyzed in light of study findings, and implications discussed.

\section{DEFINITION OF TERMS}

The following is a list of definitions for terms used in the remainder of this paper:

American: Study participants often refer to co-workers who have been born in the United States as "American." Although the term can also mean someone from Canada or Central or South America, in referring to participants' transcripts, the paper uses their voice, and the word "American."

Basic Skills: This term is often used in the literature of business education to mean base skills needed for the workplace. Although different authors include different skills, it generally refers to reading, writing, English oral communication and comprehension skills, and ability to perform essential arithmetic or math skills.

Designer or Design Engineer: This term is used in this paper to refer to the person responsible for designing a product being manufactured, or for designing the manufacturing process and work flow.

ESL: English as a Second Language. This term is used in this paper both as an adjective, as in "ESL worker" and as a noun. As an adjective, it refers to a person whose native language is a language other than English. As a noun, many study participants use the term to refer to English as a Second Language classes.

Functional-Context Education: This term, discussed further in Chapter II, is used to refer to an approach to literacy education which focuses on the functions of literacy within very specific situations or contexts, such as the workplace.

Functional Literacy: This term is discussed in detail in Chapter II. Throughout the paper it is used to refer to the ability to perform functions usually accomplished through reading or writing. 
Literate/Literacy: These terms are discussed in more detail in Chapter II. In this paper, "literacy" is used to refer to "personal" ability to read and write. It does not include the expanded skills sometimes included in definitions of literacy such as computer literacy or math skills.

Organization Communication: This term is used in this paper to refer to publications or other types of communication used by the business enterprise to inform employees of the goals and operations of the organization, or to reinforce the social and cultural norms of the company.

Process Specifications: Detailed, step-by-step documentation of steps involved in assembling or manufacturing a product. Also referred to as "procedures," or "specs." 


\section{CHAPTER II}

\section{LITERATURE REVIEW}

\section{DEFINING LITERACY}

How literacy is defined depends on who is defining it. To some, literacy is a reading-and-writing skill tied to strict "absolute" standards, such as years of schooling, criterion-based standards, or demonstrated skill in a defined set of competencies. Others define literacy more relatively in terms of the needs of people inside a particular culture or subculture (Taber, 1987).

In current speech, the word "literacy" has begun to take on an expanded meaning of competence or proficiency in almost any field. The term "computer literacy," for example, is here to stay. Dubin (1989) even cites the use of "shopping literacy" in the Los Angeles Times. This vague use of literacy as "ability to do" has both muddied and expanded the definition, touching the field of literacy in the workplace. For example, Fields, Hull, and Sechler (1987) recommend that the definition for literacy in the workplace be expanded to include such areas as science and reasoning. Most definitions of literacy still regard it as an individual's ability to read and write (Hull, 1991), though these views have become increasingly functional in nature, focusing on the applications and uses of literacy (Taber, 1987). The notion of functional 
literacy has been most influential in literacy education, particularly in the workplace.

\section{Functional Literacy}

What constitutes functional literacy? Functional literacy is a term apparently coined by the U.S. military in World War II, when certain draftees were found to be "educationally underqualified" for training or accomplishing tasks entailed in military jobs. At that time, the military compared job manuals and materials to recruits' test scores; from this information they set a fourth grade, then a fifth grade literacy equivalency level as necessary for functional literacy in the military setting. In a 1947 survey, the U.S. Bureau of Census used the term "functional illiterate" to refer to people who had completed less than five years of schooling, "on the assumption that this correlated with an inability to comprehend simple written instructions" (Levine, 1986, p. 26). Since that time a wide range of studies and governmental agencies have tried to link functional literacy to school grade level. More recently, the military has upgraded its functional literacy threshold to grade ten (Harman, 1984).

In school settings, literacy standards are still closely tied to grade levels. Carnevale, Gainer, and Meltzer (1990) note that functional literacy is more difficult to define outside the school environment because context and literacy requirements change over time. Task criteria and performance levels that are adequate in one area may not work when applied elsewhere. The kind of reading skills needed by a lawyer who must discern legal implications are different from those 
needed by a factory worker who must respond quickly to computergenerated order information or safety warnings (Carnevale et al., 1990). Still, many people continue to try to define what is required to function in society, or at work, by assigning a grade level skill equivalent. For example, a 1991 guide for trainers and human resources specialists notes:

Trainers and developers from industry and adulteducation specialists agree that a fourth-grade skill-level target for business is far too low. The reading and math materials that an adult needs to use in daily living are written at a level of difficulty far beyond a minimum fourthgrade ability. ... The twelfth grade level is the most widely accepted standard now used (1991) by business and industry for functionally illiterate workers. Though some "grunt" labor jobs may still persist, by the year 2000, the vast majority of occupations will require twelfth-grade or even thirteenth-grade skills and aptitude. (Gordon, Ponticell, \& Morgan, 1991, p. 23-24)

In the short passage above, the authors demonstrate how slippery the term "functional literacy" can be, and how easily it can be used to serve many purposes. Note that they begin by talking about "reading and math materials" in daily life, then move to a more generalized view of literacy as "thirteenth grade skills and aptitudes," although they do not define these skills and aptitudes.

The ambitious Adult Performance Level Project (APL) undertaken in the 1970s (Northcutt, 1975) has exerted a huge influence on the theoretical underpinning to adult literacy instruction and served to further institutionalize the notion of functional literacy, tacking on the additional concept of competency. Kazemek (1985) notes that "the national dissemination and widespread acceptance by educators of the APL definition of functional competency make it undoubtedly the most 
important approach to adult literacy and adult literacy education in the United States today" (p. 24). At least one early "survival" ESL text was based chapter for chapter on the APL study (Keltner, Howard \& Lee, 1987).

Since its completion, the project's operating assumption that "Functional competency is directly related in a mathematical sense to success in adult life" (Northcutt, 1975, p. 3) has colored the popular literature of education and business, although it has been challenged. Kazemek (1985), for example, questions some assumptions of the APL study, including basing functional competency on level of education, level of income and status of occupation, which led to such results as janitors with a $\$ 9,000$ income being placed in APL level 1 , while doctors with a yearly income of $\$ 75,000$ were placed in APL level 3. Kazemek also argues that the APL offers a reductive view of functional literacy since the indices of APL success are inappropriate, and may not be related to effective functioning and success in adult life. In spite of criticisms of the study, the ripples of the APL project continue to influence literacy work in both ESL and native-language programs. Kazemek notes that educators, including such influential luminaries as Jonathan Kozol, "program planners, funding agencies, politicians and the media are ... unquestioningly accepting the APL findings and recommendations as proven fact sanctioned by science and research" (p. 25).

The APL project defined functional adult literacy standards in terms of performance in a series of tasks. Since the project, the model of using task-performance criteria for determining literacy has also been assumed to be valid (see Carnevale et al., 1990). Recent literature, 
especially that aimed at business, often bundles functional literacy with the concept of basic skills. Harman (1984) writes:

Employers, it would seem, tend to prefer this more global approach to that of confining notions of literacy to reading. The term "basic skills" which includes a rainbow of components. ... more aptly defined their concerns with educationally derived job related qualifications. While functional illiteracy is of course an area of concern, there is a distinct tendency to view it in relation to other deficiencies, such that literacy becomes one, not easily differentiated element of qualificatory and performance related criteria. (Harman, 1984, p. 12)

What about the term "workplace literacy" itself? Despite the wide use of the term workplace literacy, there is no consensus as to how it is precisely defined. Workplace literacy and basic skills are often used interchangeably. Kutner, Sherman, Webb and Fisher (1991) argue that the distinction between the two terms is important, and should be maintained, especially as they apply to business and industry programs. They suggest the following distinction: "Workplace literacy and basic skills are very similar in definition, except that workplace literacy ties basic skills to performance of specific job tasks" (p. 15).

Though grade-level measures and definitions of literacy are still quite common, for example in the military, the notion of functional literacy has gradually incorporated a "functional-context" view of literacy, wherein literacy (or illiteracy) depends on the context of the situation, not on specific achievement level. The functional-context view pegs much of what is taught in programs to specific job tasks. This concept underlies much of the literature and design of workplace literacy programs in the last 15 years (Kutner et al., 1991). 


\section{LITERACY EDUCATION AS A BUSINESS ISSUE}

\section{Growing Awareness of the "Literacy Problem"}

In the last decade, media attention on functional illiteracy in the American workplace has reached fever pitch. In the late 1980s, scarcely a month went by without the appearance of a leading article on the deficiency of basic skills in the workplace, and the portentious economic consequences of ignoring the problem (e.g. "Human Capital," 1988; Qualtrough and Schamisso, 1989; Zemke, 1989). The discourse on basic skills deficiencies was, and still is, often framed in dire terms such as "crisis" or "decline" of the workforce. The very first sentence in Rothwell and Brandenburg's manual on workplace literacy programs, typical of the business training literature, reads: "The U.S. faces a major crisis because there is a growing gap between the skills employees bring with them to their jobs and the skills employers need" (1990, p. 3). A few sentences later, they state: "the literacy of basic skills crisis does not bode well for the future competitiveness of American business, especially considering predictions about the future workforce and workplace" (1990, p. 3).

Demographic changes in the workforce, technological changes in the workplace and competitive pressures are all cited as reasons to be concerned about a shortfall of skills (Carnevale et al., 1990). The Workforce 2000 report (Johnston \& Packer, 1987), widely read in industry, notes that by the year $2000,22 \%$ of new workers entering the workforce will be immigrant men and women, traditionally considered to possess lower basic skills; and that $27 \%$ of new jobs will fall into low skill 
categories, compared with $40 \%$ at the time of the report. Gordon et al., (1991) using data from Zemke (1989), assert that in the United States, $30 \%$ of unskilled, $29 \%$ of semi-skilled, and $11 \%$ of all managerial, professional and technical employees are functionally illiterate. The press also continues to reiterate such apparently incontrovertible trends as the fact that most entry jobs require at least a high school reading level, and the fact that the complexity of literacy tasks is increasing (Patterson, 1989; Gordon et al., 1991). Functional literacy gaps have been blamed for everything from costly workplace errors to the United States' new status as the world's largest debtor nation (Gordon et al., 1991). Regardless of whether functional illiteracy is truly to blame for the multiplicity of problems facing the nation, this type of media attention has made literacy an economic issue that business leaders simply cannot ignore.

Growth in Workplace Literacy Programs

A 1989 study of corporate executives conducted in Philadelphia (Omega Group, 1989) found that while employers agree that literacy exists as a serious problem in society, they have little awareness of the magnitude of the problem in their own organizations. A 1989 study by Rothwell and Brandenburg confirmed that many top managers, while aware of a basic skills deficiency in the country, believe that few people in their own organization are affected. In the Omega study, executives acknowledge that they do not know the most effective and efficient means of addressing literacy issues. They are confronting the question of whether the organization should be responsible for literacy and how to 
design effective ways to deal with manifestations of literacy problems in the workplace.

In spite of these concerns, employers have begun to increase their support of remedial training with the support of government initiatives such as the National Workplace Literacy Program (Gordon et al., 1991). Increasingly, supporting literacy programs is considered not only politically correct, but good business as well. The Business Council on Effective Literacy, a consortium founded in the late 1980s by McGrawHill, seeks support for workplace and non-workplace-related literacy programs. Each quarter, it publishes a newsletter containing evergrowing lists of workplace literacy programs in large and small industries alike (Business Council for Effective Literacy, 1988, 1989, 1990, 1991).

Larger organizations are more likely to offer basic skills training than smaller companies; by 1989 an estimated $36 \%$ of Fortune 500 companies offered some kinds of remedial courses for their employees. Of companies that offer basic skills training, $41 \%$ offer reading, $46.7 \%$ offer writing, and $30.2 \%$ offer ESL training (Lee, 1989). Though these numbers look impressive, it is important to note that of the $\$ 210$ billion business spent on all levels of training in 1985, as little as one percent is estimated to have gone into basic skills training (Kutner et al., 1991).

Judging from the program listings highlighted in the Business Council for Effective Literacy newsletter, much literacy education in the workplace takes the form of ESL training. Yet the particular issues and problems of ESL workplace literacy have not been researched well, even though demographic trends point to the need for ESL to become "an 
increasing dimension of Work Force Education well into the twenty-first century" (Gordon et al., 1991).

Not everyone believes that workplace literacy programs are always in the workers' best interest. Taking a more political view of workplace literacy programs, Fingeret (1990) believes that many programs today do not respect students' knowledge and world view. She believes that these programs limit students' power:

Employers who have problems related to workers with low level literacy skills may nonetheless be ambivalent about supporting literacy education. They may view literacy as potentially threatening to their position of power in relation to their workers and as a first step towards workers demanding better pay and working conditions for themselves. These employers may support a narrow program in which workers are trained in the use of new machines that are specific to their jobs, but are not provided with instruction in broader literacy skills. (Fingeret 1990, p. 38)

THEORY TO PRACTICE: THE INFLUENCE OF FUNCTIONAL LITERACY RESEARCH ON WORKPLACE LITERACY PROGRAMS

\section{Differences in School and Work Literacy}

The notions of functional literacy, and functional-context literacy, demand that literacy (or illiteracy) be ascertained by looking at the literacy context and specific literacy tasks. Much research on literacy in the workplace has focused on job tasks and their literacy requirements. Crismore and Mikulecky (1987) and Diehl and Mikulecky (1980) note major differences between school and workplace literacies. School tasks tend to be arbitrary, not necessarily reflective of the real demands on people in adult life. They note that students in general or traditional literacy classes do not have access to such workplace extralinguistic cues 
as machines, multiple materials, or advice from others that may affect ability to accomplish literacy tasks.

The purposes of reading at work and in school also differ. In school, students typically read books to find facts to answer teacher questions; workers ask questions twice as often as students to find information. At work, comprehending the gist or point is rarely the goal of a reading task. Rather, researchers looking at workplace literacy tasks have found that "workers read to identify facts, totally remember information, evaluate or synthesize information" (Guthrie, 1983). At school, students often work on one task at a time for long periods of time. In contrast, reading tasks in the workplace tend to be fragmented and of shorter duration. For example, people may inspect a table for just a few seconds to get the information they want (Guthrie, 1983).

In a study of 107 people in a wide range of occupations, Diehl and Mikulecky (1980) found that $63 \%$ of reading on the job can be described as reading to do, or reading to accomplish a specific, immediate task. Only $11 \%$ of workplace reading could be described as reading to learn, or reading for information to be applied or used later, whereas reading to learn is the dominant function in school settings.

Given that workplace literacy functions appear to differ from school literacy functions, it is not surprising that researchers have found that the transfer of reading skills from school to work can be difficult. Sticht (1981) found that military recruits given general basic skills training made gains while in class, but retained only $40 \%$ of course gains. But when recruits were given job-related literacy training, they retained $80 \%$ of course gains. 
Sticht's research has had enormous, long-term effects on literacy programs for the workplace. It is now commonly accepted, and strangely unquestioned, that functional-context curricula that use workplace materials help learners better transfer skills from the classroom to the workplace (Carnevale, 1990; U.S. Department of Labor \& U.S.

Department of Education, 1988). Carnevale et al. (1990) note that the primary goal of a workplace reading program should be to increase workers' abilities to perform job reading tasks, thereby increasing and enhancing their employment qualification skills, potential for retention and promotion, and self-esteem.

\section{Literacy Task Analysis}

The functional-context view of literacy education has given rise to literacy task analysis, a currently popular approach to developing curricula and classroom materials. Literacy task analysis is strongly influenced by Sticht and Philippi's design of military skills training (Philippi, 1988). It has become further institutionalized by the National Workplace Literacy Program, which has practically mandated job task analysis for programs they fund (Kutner et al. 1991).

Philippi (1988) explains why job-specific reading materials must be developed for adult learners:

Developing materials for job literacy that are contextually functional ensures that the instruction will be meaningful to the students in terms of their prior knowledge structures. Using the existing "mental hooks," or "schemata" derived from their potential work environment and experience to attach new information helps ease the process of assimilating old and new knowledge. (p. 770) 
The literacy task analysis approach calls for a job-task analysis as the first step in developing a job literacy program. The analyst (ideally the teacher) uses interviews, extensive observation, and analysis of workrelated materials to describe the job tasks in terms of performance behaviors or work activities (U.S. Department of Labor \& U.S. Department of Education, 1988). The elements of the tasks describe exactly how each task is performed. The main objectives of such analyses are to "identify technical aspects of the actions a worker performs in a vocational setting and to identify the prerequisite reading competencies needed to perform the technical aspects of the job" (Philippi, 1988, p. 660). The analyst identifies the cognitive reading process needed, and provides learners with explicit instruction in metacognitive strategies needed. A literacy task analysis approach then calls for learning objectives to be written for each job reading task, such as finding information, using skimming and scanning, and so on (Philippi, 1988).

The literacy task analysis approach appears to be founded in sound research, and has apparently produced good results, particularly in the military. However, applying it to workplaces that are somewhat smaller has been found to be burdensome and overly time-consuming, leading some to question its practical application to workplace literacy programs (Kutner et al., 1991; U.S. Department of Labor \& U.S. Department of Education, 1988).

The literacy task analysis approach and modified functionalcontext approaches tend not to consider the social aspects of individuals' jobs, nor the influence of social networks or value systems on reading or 
writing on the job. For example, in a recent influential book aimed at business readers and trainers, Carnevale et al. (1990) list "Reading Competencies Commonly Needed to Perform Job Tasks." Such questions as "How do you use charts, diagrams, and schematics?" or "How do you improve vocabulary?" are answered in the lists (p. 91). Not one of the competencies listed involves social interaction, such as asking someone for help, an obvious and common way to improve vocabulary. Patterson (1989) concludes that research has not shown a direct relationship between job performance and general literacy skills. There is, however, a much higher relationship between job performance and ability to apply reading skills. Top performers, it turns out, constantly ask questions about what they read. They use social relationships to supplement and improve their reading skills, and to accomplish the literacy task.

\section{MOVING AHEAD: NEW PERSPECTIVES ON FUNCTIONAL LITERACY AND THE WORKPLACE}

The literature on functional literacy, even a functional-context approach to literacy, has largely ignored social context, treating literacy as a discrete, individual cognitive skill. This narrow view has meant that certain research observations that have not fit the individual skill paradigm have been left without being fully explored. For example, some of the earliest military literacy studies noted that workers who seem to lack the necessary reading abilities successfully "read" occupational materials (Rush, Moe, \& Storlie, 1986), yet this phenomenon was not further explored in any depth. 
Research by Fingeret (1983), Heath (1986), Reder (1987) and Zalman (1989, 1991), among others, suggests that literacy should be viewed as part of a social fabric, rather than a set of individual skills. Newman and Beverstock argue that this type of research means that:

We cannot expect to see changes in literacy if we do not take into account its meanings and uses for a variety of literacy learners and nonlearners. And we need to know more about social networks and connections for learners that promote rapid literacy development. (1990, p. 162-163)

In light of this thinking on the social context of literacy, some have begun to question the popular, almost unquestioned belief that literacy skill deficits cause poor work performance and threaten economic prosperity. While this belief has given rise to the proliferation of wellintentioned functional-context workplace literacy programs, it also perpetuates the view of literacy learners as deficient individuals (Newman and Beverstock, 1990). When looking at job change and new literacies such as working with a computer, it is common practice to tend to focus on the individual abilities a person needs in order to interact with a program. Hull (1991) notes that if we view skills only as individual abilities, we may overlook important social components in work, such as membership in work-based communities, through which particular work practices are generated and sustained.

Fingeret (1990) is concerned about the limited view of workforce literacy programs and research. She asserts that whether workforce literacy programs use general or functional-context curricula, most still address change only at the individual level, not considering the social meanings and roles of literacy in the workplace. Fingeret also notes $(1983,1990)$ that non-reading adults do not necessarily depend upon 
print for learning, communicating information, or accomplishing tasks.

They learn from each other, and develop systems for gathering,

preserving and controlling the flow of information. Most important, they develop the capacity for dealing with tasks required of them. She writes:

These systems depend on talk, interaction, and mutual exchange. Folks help one another out, are proud of their common sense, and learn from experience. They see themselves as collaborators in social networks in which others contribute technical reading or writing skills. (1990, p. 43)

Levine (1986) believes that though the resilient concept of functional literacy has fulfilled a necessary role, it is time to define a "social context" view of literacy. Changing our view of literacy will not be easy, however. He states:

Literacy is still often treated as a discrete individual practice, severed and abstracted from the social transactions and institutional activities of which, in adult life, it is normally an ingredient. . . . A modest move in the right direction is to adopt definitions that will at least point the student in the right direction and encompass all the dimensions of literacy. . . . the first step is to discard an albatross of an idea--that literacy is a single, unified competence--and to begin to think wherever possible in terms of a multiplicity or hierarchy of literacies. . . . Functional literacy can be defined as the possession of, or access to, the competencies and information required to accomplish transactions entailing reading and writing which an individual wishes--or is compelled--to engage. (Levine, 196, p. 42-43)

Hull (1991) has written what is probably the most comprehensive paper to challenge commonly held beliefs about workplace literacy, and the program designs these beliefs engender. She questions the assumptions underlying popular beliefs about literacy, work, and learning, arguing that there is not much evidence available "between the 
company's or the country's economic demise and the basic skill deficits of workers" (1991, p. 11), and that there are plenty of reasons for work to go awry besides workers not having the requisite literacy skills. In fact, she notes there is evidence to suggest that people can acquire the literacy they need given the right circumstances, and that they regularly apply social networks and other knowledge that enable them to perform their jobs.

Hull suggests that when we look at job performance, and pay attention to how people accomplish work, and their own points of view on how work is accomplished we "come away with quite different views of both worker's abilities and the jobs they perform" (1991, p.15). She notes that the popular judgments of business executives and educational experts (for example, Carnevale et al. 1988),

... are almost never informed . . by observations which incorporate the understandings of workers. Instead, skills are listed as abstract competencies and represented as context-free and universal. At best, the skill lists are skimpily customized--for instance a job requires that a worker "signs forms appropriately" or "uses listening skills to identify procedure." (Hull, 1991, p. 17)

The enduring popularity of functional-context skill lists can be quickly verified by a cursory scan of the over 300 "workplace literacy" entries in the ERIC data base, many of which report on workplace programs and include skill lists. One hundred of 159 pages in a very recent book on occupational literacy (Rush et al., 1986) is consumed by lists of the most common vocabulary for ten different occupations, the authors stating that "the vocabulary of work, with its combination of purely technical and multiple meaning words, should provide the basis for instruction in reading a basic occupational knowledge" (p. vii). 
Based on her ethnographic study of African-American hospital workers in a Georgia workplace literacy program, Gowan (1990) has found new reasons to question the common practice of using workplace materials in literacy class--a practice based on a functional-context approach to teaching and reinforced by job task analysis. Gowan found that students in the workplace literacy class were not interested in discussing work in their literacy class, nor in using workplace literacy tasks to practice reading and writing. They felt they already knew how to perform their jobs; what they wanted was to read and use literacy to explore the world beyond their repetitive, boring jobs.

New research of this kind begins to question the conceptual validity and practical effectiveness of workplace instruction which for the most part still uses school-based models of curriculum design and teaching approach (Newman and Beverstock, 1990). Hull (1991) is particularly dismayed not so much at the recent proliferation of workplace literacy programs, but at the nature of instruction offered for workers, which tends to rely on traditional school-based notions of teaching and learning. She suggests:

Rather than assuming that structures and practices for learning literacy must be imported from school-based models of teaching and learning, we might do well to study workplaces and communities to see what kinds of indigenous structures and practices must be supported and built upon. (1991, p. 29)

The research questions this study addresses attempt to build on the notion of literacy, including workplace literacy, as a web of social networks and a complex of skills related to getting the job done. The answers may begin to shed a light on optimum approaches for solving 
the high perceived literacy problem among non-native English speakers in the workplace. 


\title{
CHAPTER III
}

\author{
METHODS
}

\section{STUDY SETTING}

\section{Tri- X Company}

Study participants come from students attending the companysponsored Workplace English classes at a large electronics firm, which will be referred to as Tri-X. Tri-X employs about ten thousand people worldwide, about eight thousand of whom work in the metropolitan area, and is one of the largest employers in the state. The company manufactures electronics and television test and measurement instrumentation as well as computer graphics equipment; certain components used in the products, such as integrated circuits and circuit boards, are also manufactured at Tri-X.

Because of economic and competitive factors, Tri-X, like other American electronics firms, has been under intense pressure to increase productivity and shore up eroding profit margins. The company has reduced the number of workers from over 20,000 in the mid-1980s to just over 10,000 in 1992, affecting people from all functions of the company, including production workers. Some layoffs were occurring during at the time this study was being conducted.

Tri-X products are highly technical, and their manufacture requires close attention to quality, detail, and exacting specifications. 
Production workers often work with very small components; some work in clean rooms requiring special garments and strict rules to avoid contamination of parts. This kind of electronics operation does not resemble the stereotypical assembly line. Walking into a production facility, one will generally see people working intently at individual workstations. The type and frequency of interaction between workers varies depending on the type of manufacturing taking place. In some areas where the study participants work, many minutes may pass with no speech whatsoever required; at other times, one might see group meetings or problem solving sessions involving more intense and frequent interaction.

Tri-X employs hundreds of non-native English speakers in its manufacturing areas, as well as in engineering and other functions. Major native language groups in the manufacturing areas include Vietnamese, Korean, Chinese, Cambodian, Lao, Thai, Mien, and Spanish. The percentage of non-native English speakers, who will be referred to as ESL workers, varies from plant to plant and group to group. While some production areas or shifts may have no ESL workers, others may employ thirty percent or more ESL workers. In groups containing a high percentage of ESL workers, native language groups tend to be mixed, although there are areas where workers of the same language background work side by side. At breaks and lunch, workers of the same language group from different work areas often eat together in the company cafeterias. 
The Workplace English Classes

In partnership with a local community college, Tri-X sponsors three levels of ESL classes called Workplace English. The classes are held two days a week for two hours in the afternoon, overlapping the first and second production shifts so that students may attend at the beginning or end of their work shift. Classes take place in a training building on the company's main campus, near most of the students' workplaces.

Tri-X began the Workplace English classes because of demand from managers and workers to "improve English" among non-native speakers in the workplace. Although general ESL classes had been available at the community college center on campus, managers and students who talked to the researched before the beginning of the study felt that these classes were ineffective and did not address the needs of Tri-X workers. A few areas of the company had previously hired English teachers to conduct small classes at the worksite. These private on-site classes were considered effective in upgrading English skills for the workplace, but they were very expensive, and because ESL workers are spread throughout the company, very few students could take advantage of the classes at any particular worksite. Because the private classes were small, students of very different skill levels had to attend the class together, causing some dissatisfaction.

When budgets no longer allowed managers to hire private ESL teachers to come into the work sites, the Tri-X corporate training department worked with the community college to put together centralized ESL classes for employees that would focus on workplace 
language skills. Since the three levels of classes formed are expected to serve employees company-wide, they cannot focus on issues of particular work areas; instead, teachers build parts of the curricula using company-wide workplace materials and issues. Teachers interview Tri-X managers to ascertain employee language issues, and work with students at the beginning of the term to determine their language improvement needs. The beginning level class tends to focus more on developing basic literacy skills than the second and third level classes, which assume a higher level of literacy.

Because the class is publicly funded, students from outside Tri-X may attend classes, but very few students from outside the company actually come. The community college allows open enrollment, meaning students can begin the class at any time during a term. Class sizes therefore vary not only from term to term, but from day to day. Like other adult education classes, it is rare to find exactly the same people in class on any two days of the term, since work and family demands take students away. Generally, the Workplace English classes are small, containing five to ten students.

\section{STUDY PARTICIPANTS}

\section{How Participants Were Chosen}

Human Subjects Review approval was applied for and granted before involving any of the study participants. At the beginning of each of three school terms, the Workplace English teachers asked all Tri-X employees attending the classes to participate in the study. Only students employed by Tri-X were invited to participate. The researcher 
then came to the classes and explained the reason for the study and the process involved. After hearing about the study, a few students declined to participate, but all but two agreed to participate. Because some students dropped out during the term, in the end nineteen students successfully completed the in-depth interview process. The researcher returned to classes until all students who consented to participate had been interviewed. Though the researcher was employed at Tri-X as a manager in the corporate training department, she had not met the participants before the study began; a few participants said they knew the researcher by sight from the workplace.

\section{Participant Demographics}

Nineteen students participated in the study. The group includes thirteen women and six men from seven different language groups, ranging in age from 30 to over 50; their average age is approximately 41 years old. Some students declined to give their age; in these cases the researcher estimated age based on students' appearance and life history.

Study participants include seven different ethnic groups. Six participants are Vietnamese, five are Korean, two are Cambodian, two are Mien, two are Thai, one is Irani, and one participant is Lao.

The study participants are not new arrivals to the United States, averaging 15.2 years in this country. All but one of the nineteen members of the group have worked at Tri-X for ten years or more; the average length of employment is 12.3 years. Nine participants began working at Tri-X within two years of arrival in the United States. In age and length of employment at Tri-X, study participants closely resemble 
the general Tri-X employee population, which is characterized by an average age of about 41 years and length of employment of over 10 years.

Seven participants received the equivalent of a high school education before beginning the Workplace English class. Two of these attended one or more years of high school in the United States; the others received high school education in their native countries. Four students attended college in their native country before arriving in the United States. Six students had less than five years of formal education in their native countries, five of these women. All students said they could read "some" in their native languages; the two Mien students identified their native language literacy ability as very minimal. All but two of the study participants had attended some ESL instruction before the Workplace English class, although most had difficulty recalling the exact number of months or years attended. Table I summarizes demographics of the study participants.

\section{DATA COLLECTION}

\section{Participant Interviews}

Because the heart of the study inquiry involved ascertaining attitudes and approaches to literacy and literacy functions in the workplace, in-depth interviews formed the core of the data collected. After signing a written consent form to participate, each student participated in a structured interview with the researcher in a private room in the Tri-X training facility (see Appendix A for a sample of the Consent Form document). Interviews were conducted during Workplace 
TABLE I

DEMOGRAPHIC SUMMARY

\begin{tabular}{|c|l|c|c|l|c|c|l|l|c|c|}
\hline No. & Alias & Sex & Age & $\begin{array}{c}\text { Ethnic } \\
\text { Group }\end{array}$ & $\begin{array}{c}\text { Years } \\
\text { in.S. } \\
\text { U.S. }\end{array}$ & $\begin{array}{c}\text { Years } \\
\text { Previous } \\
\text { Education }\end{array}$ & $\begin{array}{c}\text { Language } \\
\text { Spoken }\end{array}$ & $\begin{array}{c}\text { Other } \\
\text { Literacy }\end{array}$ & $\begin{array}{c}\text { Prev. } \\
\text { ESL? }\end{array}$ & $\begin{array}{c}\text { Yrs. } \\
\text { at } \\
\text { Tri-X }\end{array}$ \\
\hline 1 & Song & F & 30 & Lao & 16 & 12 & Thai, Lao & Lao, Thai & Y & 10 \\
\hline 2 & Vinh & M & 46 & Vietnamese & 17 & 14 & Vietnamese & Vietnamese & Y & 12 \\
\hline 3 & Paula & F & 40 & Cambodian & 12 & 3 & Cambodian & Cambodian & N & 12 \\
\hline 4 & Foo Lin & M & 28 & Mien & 11 & 1 & Mien, Lao & Mien & Y & 2 \\
\hline 5 & May & F & 36 & Mien & 13 & 0 & Mien, Lao & Mien & Y & 10 \\
\hline 6 & Tou & F & 40 & Thai & 20 & 4 & Thai, Lao & Thai & Y & 10 \\
\hline 7 & Bong & M & 50 & Korean & 14 & 16 & $\begin{array}{l}\text { Korean } \\
\text { Japanese }\end{array}$ & Korean & Y & 13 \\
\hline 8 & Li & F & 54 & Vietnamese & 17 & 12 & Vietnamese & Vietnamese & N & 13 \\
\hline 9 & Haing & F & 49 & Cambodian & 17 & 3 & Cambodian & Cambodian & Y & 15 \\
\hline 10 & Kim & F & 39 & Korean & 15 & 12 & Korean & Korean & Y & 12 \\
\hline 11 & Yung & M & 37 & Korean & 16 & 12 & Korean & Korean & Y & 15 \\
\hline 12 & Tina & F & 38 & Vietnamese & 16 & 12 & Vietnamese & Vietnamese & Y & 15 \\
\hline 13 & Inae & F & 47 & Korean & 13 & 12 & $\begin{array}{l}\text { Korean } \\
\text { Japanese }\end{array}$ & Korean & Y & 13 \\
\hline 14 & Loan & F & 32 & Vietnamese & 16 & 12 & Vietnamese & Vietnamese & Y & 11 \\
\hline 15 & Fatima & F & 50 & Iran & 13 & 17 & $\begin{array}{l}\text { Farsi } \\
\text { Azerbaijani }\end{array}$ & $\begin{array}{l}\text { Farsi } \\
\text { Azerbaijani }\end{array}$ & Y & 11 \\
\hline 16 & Tuan & M & 40 & Vietnamese & 14 & 9 & Vietnamese & Vietnamese & Y & 10 \\
\hline 17 & Mimi & F & 40 & Thai & 15 & 5 & Thai & Thai & Y & 16 \\
\hline 18 & Sook & F & 42 & Korean & 17 & 8 & Korean & Korean & Y & 13 \\
\hline 19 & Henri & M & 40 & Vietnamese & 14 & 14 & Vietnamese & Vietnamese & Y & 10 \\
\hline
\end{tabular}


English class time and lasted from fifteen minutes to approximately half an hour.

Each student was asked questions from a structured interview guide; additional questions were asked for clarification, or if a student brought up a question or concern. To put students at ease, some interviews began with ice-breaking conversation not included in the guide. Similarly, the researcher occasionally did not require answers to questions in the interview guide if they clearly embarrassed the student or the student did not understand them. Interview questions covered demographic information and in-depth information about the job participants and job processes, social interaction on the job, and language and literacy use on the job. A complete interview guide is included in Appendix B.

All interviews were tape recorded with the participants' agreement and later transcribed by the researcher. A sample transcription appears in Appendix C. Transcripts were analyzed for content, focusing on recurring themes and patterns in the data and notable exceptions to prevailing themes.

\section{The B.E.S.T. Test}

To obtain information on the relative literacy and language ability of the study participants, the researcher planned to give all study participants the Literacy and Core section of the Basic English Skills Test (B.E.S.T.) published by the Center for Applied Linguistics (1984). The B.E.S.T. is intended for use with limited-English speaking adults to give information on the attainment of basic functional language skills. 
The B.E.S.T. Literacy Skills test presents a number of different reading tasks from reading food labels and prices to reading newspaper want ads. Writing tasks include personal information, addressing an envelope, writing a check and writing two short letters, one explaining an absence from school and the other thanking an American friend for a gift.

The B.E.S.T. Test Manual states that the test is designed to provide information in three basic areas including: a) evaluating language proficiency for placement or entry into language courses, or for planning individualized learning activities; b) determining the progress of individual students, or the class as a whole, in developing functional proficiency in English; c) providing diagnostic feedback about the students' acquisition in each of the particular language-use tasks included in the test.

Additionally, the B.E.S.T. could give some indication of students' ability to profit from on-the-job training course. The test manual states that,

Although the B.E.S.T. is not intended as a placement or achievement test for vocational training courses taught wholly or primarily in English, it can serve as a screening device in that students who do not perform at a very high level on the tasks represented in the B.E.S.T. would not be expected to have sufficient language proficiency to profit from most English-medium vocational training courses. (Basic English Skills Test, 1984, p. 1)

On two separate days, ESL teachers administered the B.E.S.T. Literacy Skills Test to all students in Workplace English. Nine study participants were present during the test times and completed the literacy portion of the test. The other ten students were not attending class that day. After the ESL teachers gave the literacy test, the 
researcher decided to discontinue literacy testing and not conduct oral interview testing because students, especially at lower proficiency levels, feared tests would be used against them in the workplace, or results would be used to justify laying them off (see Study Limitations, Chapter VI).

Document Analysis

Four types of typical literacy documents encountered in the workplace were analyzed for content, readability, and organization.

Readability was analyzed using the Fry Readability Scale (Fry, 1978); for each document analyzed, three passages of 100 words were chosen at random. For each passage, the number of syllables and the number of sentences were counted and an average for all three calculated. A grade level readability was assigned based on these numbers using the Fry scale.

Documents were also analyzed for other factors that might affect readability such as charts, tables, illustrations, and organization. Documents analyzed were:

1. Manufacturing process specifications, also called "specs" or "procedures." Twelve process specifications were obtained from one of the manufacturing areas where several of the study participants work; three of these were chosen at random for detailed analysis.

2. Three issues of the Tri-X Weekly News: the December 4, 1992 , and January 8 and 15, 1993 issues of the Tri-X company newspaper.

3. Two letters to all employees from the company CEO.

4. The company Benefits Workbook. 


\section{CHAPTER IV}

MAKING IT WORK: PARTICIPANT VIGNETTES

\section{INTRODUCTION}

This chapter includes six vignettes featuring individuals from different ethnic backgrounds, who possess a range of individual literacy and verbal skills. The vignettes are included to show how study participants integrate their own individual literacy skills, networks of literacy helpers, and other strategies to perform literary functions and work processes, and how they hope to use the Workplace ESL program to improve. Of the 19 study participants, any participant's story would show this integration. These six vignettes were chosen because they best illustrate strategies used by participants with low personal literacy skills contrasted to those used by participants with higher personal literacy skills. They also were chosen to represent a range of ethnic groups, previous education and age. May and Haing possess among the lowest literacy skills in the group, while Vinh and Song possess the highest. Haing's vignette was chosen because she is the only person in the group who openly reported intercultural problems at work, an issue which needs further exploration. Sook's vignette is discussed as an example of a person with acknowledged work expertise, achieved without access to advanced personal literacy skills. Yung's vignette was selected as an 
example of a person using minimal social networks to accomplish his job.

In the first vignette, May shows the innovative strategies that a person with very limited literacy skills has put to use to succeed in her job. May's vignette also demonstrates how strong interpersonal relationships and English verbal skills contribute to her ability to get along without reading or writing. She also provides a good example of the important role that memory plays for many of the participants in learning and doing the job; where others use documentation as their memory, May, who is from a pre-literate culture, commits entire work processes to memory. She learns quickly, but must watch someone do a job before she can learn it. May is a person whose literacy aspirations are modest; she just wants to read and write a little better. May is one of the few participants taking Workplace ESL specifically to improve on her current job.

The second vignette looks at Haing, who like May possesses very limited literacy skills in her native language. Unlike May, Haing has been working at her current job for a very short time so she has not been able to put together comfortable helping networks or implement alternative literacy strategies. Haing lives in fear of making a writing mistake her boss will discover, and has encountered unfriendly attitudes from her co-workers. She is attending Workplace ESL to improve her confidence in using verbal and written English.

Yung, a Korean whose spoken English is much more difficult to understand than May's or Haing's, is featured in the third vignette as an example of an ESL student who reports that he gets through his work 
day with little verbal interaction, and very little writing. Yung uses his intermediate reading skills, along with a bilingual dictionary, to read procedures and do his job; he uses the same person consistently for any help he needs with reading.

Vinh and Song, in Vignettes 4 and 5, are the study participants who possess the most advanced individual literacy skills; Song's verbal skills are also the most native-like of the study group. Both also serve as literacy resources in their own communities. Vinh and Song are examples of non-native English speakers who have attended community college vocational training to further their careers; more than most others in the group, they read to learn. However, Vinh and Song, unlike Yung, do not rely on reading and writing alone to perform quality work. They consider verbal communication important to achieving quality work. Song believes that verbal skills, not literacy, are holding her back from advancing.

The last vignette looks at Sook, a Korean woman with low-level reading and writing ability who is clearly an expert in the manufacturing processes in her area. Other workers, including engineers, regularly consult Sook for help with process design or problem-solving on the job. Sook's preferred strategy for success is to work closely with process designers before procedures are written; this assures she can read the process specifications. She also scans new specifications for changes, and asks for help before proceeding. Although Sook has been very successful in her current job without advanced literacy skills, she believes she needs to improve her reading in order to advance. 


\section{VIGNETTE 1: MAY}

May is an outgoing 36 year old Mien woman who came to the United States as a refugee from highland Laos in 1979. Like most Mien women of her age, she did not attend school in Laos. This is May's third term in the Workplace ESL class. She briefly studied ESL 11 years ago at a refugee program where she could take her children and "learn $A B C D . "$ May can read just a few things written in Mien, which she learned to read from her husband. Her English reading skills are minimal, and beyond the basic literacy classes she took 11 years ago, mostly self-taught. Despite her limited literacy skills, May is very fluent in spoken English and easy to understand.

May has been working at the company ten years. She got the job when her husband asked his manager to hire May so that they would have enough money to buy a house. May is proud of the fact that they bought a house after only four years in the country, and have since sold it and bought another. At Tri-X, May builds circuit boards. She has worked with the same group of about 15 people for ten years, so everyone knows one another well. May says of her work group, "It just looks like family." People talk together frequently, to alert each other to something like a wrong part or to solve process problems. They also just socialize, joking or talking about families or personal problems. May says she has learned all of her English at work; she is the only Mien person in her group, and speaks only English at work.

May learned her job by being shown how to do it. She explains, "Our supervisor, she showed me what they do, how they do that. After 
that, I just follow that." May is responsible for knowing the information in the written process procedures, but they are very difficult for her to read; she prefers to follow schematics rather than written steps. Mostly, May has her work procedures memorized, so that she does not need to look at the procedures every day. When she gets a new procedure, or has to learn something new on the job, she asks a friend in the group, a technician, or even her supervisor to help her.

May is expected to write a note when she encounters a part that is dented, broken, or not working. She can write down the part numbers, but does not know how to write a note explaining the problem. May tells the technician in her area the problem, and the technician helps her write it down. After the technician writes it, May copies down what he has written, and puts it in the bin containing the same kind of parts that had the problem. The next time she encounters that problem, she just copies the note she has posted in the bin. She says she can always remember which one is the right note.

From time to time, notes and memos circulate in the group. May can read the easy ones, like the time and place of a meeting. Otherwise, she asks someone in the group for help. Another way she finds out what is in a letter or memo that everyone has received is by listening to people talking about it. She hears them talking, asks if they are talking about the letter, then knows what the letter is about.

May is attending ESL class because she is anxious to learn more reading and writing, even though she believes she does her job well now. At home, she never speaks or reads English. Her husband does most of the reading for the family. Her three children also help. But for the last 
two years, May has been paying the bills for the house. Writing checks is difficult, especially spelling the check amount. "When I start, my son he had to follow me all the time. When I go shopping, my son go with me to write down the check."

"It's very hard to learn," May laments. "Everything's very hard." To May, writing means spelling words. Sometimes, she knows a word, can say the name, but is very frustrated because she cannot spell it.

\section{VIGNETTE 2: HAING}

Haing is a 47 year old Cambodian woman who has been in the United States since 1975. She attended school in Cambodia through about third grade, just enough to learn to read her language. After that, she says, her old-fashioned mother:

... didn't want to send me to school no more because she afraid I gonna write a letter to my boyfriend or something. The men, she let the men go farther an' get a degree. The woman--my family don't want to go.

Haing attended ESL for one year after arriving in the United States, but until she enrolled in the Workplace ESL program this year, she had not been to school in 12 years.

Haing has worked at Tri-X for fifteen years. She now works in a circuit board manufacturing area with nine other people--four on the assembly line and five in engineering. The workers on the assembly line can rotate through jobs like soldering, screen printing, and dye mounting as they need to be done. When Haing arrives at work, she looks at the whiteboard to see what work needs to be done for the day. Haing can read the schedule board easily, since it contains mostly numbers, 
although occasionally someone writes a note with instructions or requests for the day shift.

Haing is very careful about the quality of her work, and considers her job very important. If she makes an error on a dye, it can cost two or three thousand dollars. Haing has to read process specifications at work, including short process change notices called "mini-routings." Workers are held accountable for the information contained in miniroutings. When Haing gets a new procedure or update to learn, she can read some of it, but not the hard words. If she cannot understand something on the mini-routing, she asks someone who works on the line for help. She says that some of them give her "a bad look" when she asks for help, but if people don't want to help her she doesn't ask them again. Haing knows she has to be very exact, but claims she never makes mistakes. If she is not sure what to do, she waits until someone who knows what to do comes by and then asks that person. She talks to the engineers as well as the people in the production line.

Although Haing does not have to write very much at work, once in a while she needs to write a note for someone with a message like "This job needs to be done" or "This dye is short." Haing is very concerned not to make a mistake in her writing; she asks people at work to help her with hard words, but is cautious who to ask because she is afraid that someone will report the mistake or the fact that she can't write to her boss. She feels her boss is not patient with her. Haing says she tries very hard, in spite of these people. "People is mean," she relates:

That's why I before I ask I have to watch out. Some boss don't patient with whoever, like me Cambodian, my age 45 almost 50 years old and come to United States and learn a 
second language is hard. I try my best to work, do a good job and to learn English and get in touch with American people. They have to understand that. They should not just say, "You do not speak English well, I don't understand you." It's a hurt feeling. Because I try, try hard. To work good, to understand English good. I try. But that's all I can give. You know, that's all.

To improve her English and her work situation, Haing is attending the Workplace ESL class at Tri-X. She says the class has helped her a lot, especially with writing. Before she attended class, she didn't want to write at all because she was afraid she would write something wrong. Rather than write, Haing would go straight to the person she had a message for and talk to them. Since coming to class, Haing tries to write at least the easy words on notes, and tells the person for whom the note is intended, "If I do wrong, just correct me." Haing is also trying to improve her English while at work. When she sees or hears an unfamiliar word, she writes it down on a piece of paper and then finds someone to explain the meaning to her.

At home, Haing doesn't read or write much, since she has little time due to her housework. Except for paying bills, there is no chance to practice her literacy skills outside English class or the workplace.

\section{VIGNETTE 3: YUNG}

Yung is a quiet man, about 37 years old, who came to the United States from Korea 16 years ago. He attended school through high school in Korea, and can read and write Korean. He has been working 15 years at Tri-X, where he has held jobs in several different divisions. Yung 
speaks quickly and confidently in English, though his syntax and accent are sometimes difficult to understand.

Yung is now working in $\mathrm{QC}$ (Quality Control) for Tri-X, where he is responsible for automatic testing of completed electronics instruments. Seven people work in Yung's group, one from Vietnam, another from Puerto Rico, the rest "American." Yung says he doesn't talk much with the people he works with, "only when necessary." First thing in the morning, however, the group talks about the schedule for the day, and discusses any problems that need to be fixed.

When an instrument is completed, the final assembler brings it to Yung on a cart, and he puts it through the automatic test. Yung uses a computer to do the testing, putting the instrument through several tests. Although Yung knows a lot of the jobs in the area, he spends most of his time testing. Occasionally, if he has extra time, he builds final instruments. When Yung is testing, he reads the pre-programmed computer for results; it tells him whether the instrument has passed or failed, and identifies the source of failures. Then Yung writes down the instrument name and serial number and the results of the test. If the instrument has failed, he passes it to a technician for repair; if it has passed, he sends it on to a function called cabinetizing.

Yung's job does not require much writing other than recording the instrument numbers, test results and types of errors from the computer onto a small piece of paper and sticking the paper on the instrument. He does not have to program the computer, just type in passwords and punch a few keys for testing. The messages he reads from the computer are similar from day to day, a combination of words and numbers such 
as error type and number of strokes. Sometimes, Yung needs to read procedures. If something is wrong and Yung thinks he can fix the problem himself, he reads the procedure and compares it to the instrument he has; sometimes he can discover the source of the problem on his own.

When Yung receives memos or notes from the company, like a recent report on a jogger who was attacked in a nearby neighborhood, he can usually get the gist of the letter. If he doesn't understand, he sometimes asks a woman nearby in a similar job for help. He asks her if she has read the memo, and if she has read it he then asks her the meanings of words he can't understand. Yung usually avoids asking his manager for help on small reading tasks. He asks the manager only when the message has to do with "important things like lay-offs or future forecasting." Yung says he can read most things at work. He keeps an English-Korean dictionary at work, so that he can look up difficult words that he comes across.

When Yung needs to learn something new, he asks a trainer or lead person, and they explain it to him. Sometimes he makes notes of numbers of parts or components during the training. But, he says, "I don't write in the sentence."

Yung attended ESL class for a few terms several years ago, then quit and now is starting again. Yung is interested in improving his English conversation skills, since he speaks only Korean at home and has no chance to practice English. At home, he reads Korean newspapers; sometimes he will pick up an Oregonian at lunch time at work. 
VIGNETTE 4: VINH

Vinh came to the United States from Vietnam in 1975. He completed high school and two years of college in Vietnam, where he studied math, before he had to join the Army and fight in the war. Vinh attended some English classes at the community college after he started work for Tri-X 12 years ago. After that, he worked at night and went to class during the day for two and a half years to study to be an electronics technician. At college, Vinh used reading to help him learn--it was easier than listening. Vinh remembers that while he was studying to be a technician, math, physics and chemistry were very easy for him. English, however, was difficult. He says,

English maybe very hard for me. Sometime I understood something my teacher talk, sometime maybe I skip, because I don't understand. Maybe the book help me--it helps me so much in study. I read the book--no problem.

Vinh has worked his way up from entry level to his current position of Technician 2. Vinh does pre-calibration, calibration and repair of television test and measurement equipment. He works in a large group of about 30 people; he is the only person who speaks Vietnamese in the group, and always speaks English at work. Vinh and his group get along well. If there is a little extra time, they sometimes talk about personal things. They might talk about Vietnamese culture or American culture. Vinh says people ask him, "How is your country now? How is your family?"

Vinh believes in teamwork to build the best product. He and his co-workers talk a lot; they work together to solve problems. He 
sometimes asks for help, but also gives it, "Because we have teamwork," Vinh says, "so we should help each other improve the quality of the instrument." Once a week, the team meets to discuss goals, quality, schedules, or ways to satisfy the customer. The manager asks for new ideas; if someone has a new idea to improve the process or the product, they answer. Vinh sometimes contributes new ideas to the group.

\section{VIGNETTE 5: SONG}

In Laos, Song attended about nine years of school, where she learned to read and write Lao. After arriving from Laos when she was 15 years old, she attended three different high schools in the United States, but finally graduated from a high school in Portland. Song also speaks Thai, a language very closely related to her native Lao. Based on her verbal language proficiency in her study interview, her teacher's reports, and her self reports, Song probably is the most proficient study participant in verbal and written English.

Song works in a stockroom materials management area of Tri-X, where she issues materials and ships them to the production floor. Unlike other study participants, Song has never assembled products. She has worked in the stockroom for her entire ten years at Tri-X. Although the job function of supplying materials hasn't changed much in that time, she has had plenty of different experiences on the job, such as setting up a new just-in-time materials management system, talking to buyers, and learning new computer systems.

When a production worker needs parts to build a product, they turn in a small, pre-printed card that tells Song what they need. The 
card shows the part number, quantity, and destination. Song reads the card, picks out the parts, then "downgrades" or subtracts the parts used from the computer inventory system. Then she takes the part to the area written on the card and gives it to the requestor. Sometimes, she hands the parts to them in person, but more often, she just puts the parts on a cart in the area where people can come to pick them up.

Although Song would rather work days, she works swing shift with three other people. She seldom sees her boss. Each day, the swing shift meets with the people from day shift for half an hour before starting work. During this meeting, the day shift shares problems that the swing shift needs to know about, or asks them to finish a job that they could not complete. If the day shift production people have a message for the stockroom, it is often relayed to Song in this meeting.

Because only a skeleton crew works during swing shift, Song sometimes leave notes to convey messages to the buyers, who work during the day, about such things as problems with parts or discrepancies between part counts and the computer system. Song's boss occasionally sends out memos that talk about division sales and results; she has no trouble reading these memos. Song also reads the company newspaper every Friday. Although Song has to read problem notes and order cards, she says she could easily get through a day without having to write anything at all on the job.

Nowadays, it is a rare occasion that Song asks for help with reading or writing. When she does ask for help, she asks a younger American woman who works with her, who has a college degree and is very patient. Usually Song just asks for the meaning of individual words 
she can't understand, since, she says, "I can get the solution if I read the whole thing, I can understand what they want."

Song has asked people to help her write in the past. At first, she was afraid of writing. Then she went to a friend and asked her for help. She relates:

I said, "Can you help me write?" And a friend of mine said, "No, I don't want to help you. You gotta learn how to do yourself." First I get mad--you know, that this person don't want to help--and when I start writing I say, "Oh, yeh, she's right. I should learn how to write because it's help me to understand." So now I start write my own self.

Now Song writes small notes to other shifts, as well as E-mail messages on the computer, because it is difficult to get in touch with people over the phone. Song likes writing on E-mail better than writing messages by hand. She believes using a keyboard encourages her to write more. In her last job at Tri-X, Song was asked to write a work procedure book before she left. Although that task was difficult, she was able to complete it by writing sections, going back and making sure others understood it, and then re-writing.

Song has attended materials handling certification classes at the community college. She plans to take a personal computer class this year so that she can buy her own home computer. Song feels her writing is getting better and is determined to do her own writing now because, she says, "I don't want to keep asking people to help all the time." Song would like to be able to write more on the job, so that she could learn more. She believes the Workplace ESL class helps her a lot with her writing. 
Song acts as a literacy resource for other people outside the workplace, usually Lao or Vietnamese friends who ask her for help in writing. Sometimes people at work will ask her to phrase something or write it out. She is surprised that Americans occasionally ask her to write out a problem about something at work.

When Song has to learn something new at work, it is usually a new procedure. Sometimes, Song says, the people who write the procedures don't phrase them very well. If she doesn't understand a section, she goes back to the person who wrote the procedure and asks them to show her how to do it. Once she sees it done she can pick it up. She sometimes goes back to the procedure once or twice, but after that doesn't need it any more.

Song worries that her biggest problem at work is with her verbal skills:

I have the biggest problems verbal. I really like to practice a lot. Speaking. Because it seem like more problems verbal than writing because for any jobs when they interview you they say "She's not good at verbal," things like that. It's hard to get a job anywhere else. They look at your communication skill. Myself, I don't think I have much problem with communication skill. Some American will say because she's Asian she will have problem with communication skill, but they look at the wrong way because some people Americanto-American they still have problems with communications. Seems to me if you know the person she's hard to understand she might understand better if you have hands on, show her things, like that. If you just talk to her, she wouldn't understand, so you just show her how to do it.

\section{VIGNETTE 6: SOOK}

Sook is a 42 year old Korean woman, who has been in the United States 17 years, and speaks English fluently. She can read and write 
Korean, but can not remember exactly how many years of school she attended in Korea; she thinks it was about eight or nine years. Despite her excellent verbal fluency, Sook attends the beginning level Workplace ESL class, which focuses on literacy. Sook's English literacy skills are low, at about the same level as Haing's.

Song has worked at Tri-X for 13 years. She describes herself as an assembler, but she does many different things during the day. In her area, the group assembles the entire circuit board, from start to finish, which entails a number of different steps and processes. She says, "I am assembler, but we do so many different things all days it's kinda hard to pinpoint. I bond. I hand assemble, hand solder, cast." Song has been working in the same area since she came to Tri-X, and she speaks authoritatively about her work. She is modest about her abilities, but is clearly regarded in her work area as an old hand; she trains new employees, and also collaborates with engineers in developing work processes before procedures are written. She says that though there is a manager in her area, "most of the time, because I'm there forever, people asking me questions." Despite her limited literacy skills, Sook says she sometimes helps people "read" the procedures by showing them how to do a process.

When the manager releases a new job, he circulates a minirouting, an update of the process specifications (specs), that workers are expected to follow. Mini-routings are the most important documents that Sook is expected to read on the job. Sook says she can read most of the mini-routings now, but at first she had a lot of difficulty reading process specs. To learn the specs, she took them home and asked her American 
husband to help. She also looked up some words in the dictionary. Now, if she encounters a hard word in a specification or mini-routing, she asks a co-worker for help. She feels it is important to read the miniroutings every day, especially to scan for changes, since engineers sometimes make changes without telling the assembler.

Sook thinks that engineers need to learn to write the specs better, and avoid using "engineer language,"--hard, technical words. The best way to ensure that people can read the procedures, she believes, is to work with the production people in the design and writing of the procedure. Sook observes:

It's a lot easier when they come to talk to the people who's gonna do the work. Actually production people. To sat working with them instead of just talking, "Here's your spec, this is your drawing." Sometime, most of the time it doesn't work that way, you know. Things don't work the way they predicted. So we have to kind of change the design a lot to make the order to work.

Occasionally, Sook has to write a note to another shift, or read notes from other shifts. Her manager also leaves her messages on the whiteboard, which she usually can read. Sook describes her reading and writing difficulties:

I have problem with handwriting. Ya know, it just depends. You know because I don't have much background education, junior high, and I was too lazy to learn when I was younger age so because I learn a little bit here a little bit there by myself it's hard for me to put together. Like disorder. When I write something kinda disorder. The letter should belongs to front, goes in back.

Sook believes that she would have much more opportunity at work if she could read and write more easily. She is taking English class to improve her literacy skills. She describes her goals: 
I like to read ya know without problem. I read this, I have to take time I need to put together. I wish I can just sit down, read, understand. Faster. Then also if I reach that goal then I like to read long, hard texts. Read about computer systems. . . . I had a lot of opportunity before because I know what I am. I'm not comfortable now because of reading. I just wish I can pick up fast enough. 


\section{CHAPTER V}

\section{RESULTS \\ INTERVIEW RESULTS}

"Satisfy Customers:" How Participants Talk About Work

After ascertaining participants' demographic profiles, the researcher asked students interviewed to describe their current job.

Though these descriptions were meant to provide context for exploration of language interaction and literacy use on the job later in the interview, how participants talk about their jobs reveals important information on how they view their role in the workplace, and their proficiency in the vocabulary and idioms of work.

A Large Vocabulary of Work. Study participants talk knowledgeably about their jobs, but display a wide range of fluency. To varying degrees, they are all able to describe their work, some in step-bystep, painstaking technical detail. All use job-specific words profusely, but when asked to translate specific words for the researcher, they often encounter more difficulty. For example, May describes where her product goes when she is finished with it:

May: I make the whole thing and then after that give another person KOC. KOC means they have to test again whole thing.

Interviewer: What does $\mathrm{K}-\mathrm{O}-\mathrm{C}$ mean? 
May: K-O-C--I don't know--they call it KOC. I don't know what that means. But after that we put the whole thing and we put in the cycle--the cycle look like a big microwave, a big one.

In a few cases, the researcher had difficulty understanding participants' syntax or accent, and had to ask for clarification a number of times; in these cases it became clear that participant workers rarely talk about work processes--they just do them. But even students whose grammar and syntax made it difficult to understand used technical vocabulary without hesitation. Below is a partial transcript of one Thai woman describing her job, which she has been doing only for a few weeks, after switching from a different area where she worked 16 years. She is speaking very quickly. The technical, job-specific words are underlined.

I do laser trimming. It's we have substrate make out ceramic but circuits run all the way, ya know, how the small that chip they call we call the parts like hard to describe if we see. Anyway they put some gold-run how the schematic stuff like that but usually it be circuit board like that but this substrate like from what you do ceramic. Okay, they have the B-substrate like from the what do you call ceramic. Okay they have the gold run sometime they put cap, green cap in that like that. I don't know how to describe, I may understand what going on but explain to somebody else not easy. But anyway they just kinda like a DEC screen print. You know what it is, OK. They go run, but after that how many value the part we have to trim. How many sometime we not exactly, we not exactly can print value supposed to be. Ya know the customer orders a certain way, how many $\underline{\mathrm{K}}$, how many ohm, how many have to be have to trim. If you cut trim, how many it 'sposed to be.

The Job in Context: Participants' Contribution to the Whole.

Participants were asked not only to describe what they do every day, but where their work comes from, and who it goes to next. Every person interviewed is familiar with the part their job plays in the overall 
manufacturing process, at least within their plant. Though some focus on their specific job task in describing their work, such as "building circuit boards," or "final assembly," it is surprising how many talk about customers and end-products, and describe their work in terms of "satisfy customer" and achieving quality. These participants see their work not just as a series of tasks, but as part of a larger process extending far beyond their individual jobs. Vinh, for example, describes why he has to put his instrument in the oven when he has finished testing it:

Because some component change with the temperature. Maybe the instrument go to Africa, so hot weather, maybe some component die because hot. Maybe go to Alaska, some component die because too cold. So we need to cook the instrument.

Another participant who manufactures circuit boards was asked about the product the board goes into. She replied:

Product? I'm not very know that one but the product they call the 3001, 3002 and now have another one they call the-I don't know. New one we make the telephone. They sell one for three thousand dollars for one telephone.

These workers clearly know the vocabulary and idioms of their job, though they demonstrate different levels of skill in talking about their job. They also know what part they play in the process, an important knowledge since, as further interview results show, the most prevalent function of literacy on the job is to assure smooth and consistent manufacturing process among individual workers and across groups.

\section{Verbal Interaction on the Job}

Because one of the central questions of this study asks whether and how individuals in the workplace use networks or social 
relationships to complete literacy functions, every interview with study participants contained questions about their verbal interactions with others on the job. Participants described the size of their workgroup, how they interact verbally with others, and what language or languages they use.

Work Group Size and Frame of Reference. Participants report the size of their groups from three to "more than 40" people. These selfreports may not accurately reflect the number of people with whom participants actually interact at work, since transcripts show different frames of reference for work group. Some define their group as everyone involved in product assembly from start to finish, while for others, work group may mean the two or three people they work with on their section of the line. Work group size does not appear to determine how much verbal interaction people experience; need for information and desire to maintain relationships and the structure of the job are more important.

Languages Spoken. All participants report speaking English at work. Outside of break times and lunch periods, when people congregate in cafeterias, most speak no other language but English on the job; only three participants said they speak their native language at work from time to time. Most participants work in areas containing people of diverse language and ethnic mix; they speak their own language only if they by chance work with another person from their country. One Vietnamese woman who works with another Vietnamese says she often speaks English with her countrywoman since other workers around them cannot understand Vietnamese. But people report seeking out others 
from their country at breaks or lunch and speaking their native language, because it is "easier" or "more relaxing."

Topics of Conversation. Most of the conversation on the job concerns work process or work flow. In the course of a day, the participants talk constantly to assure quality and smooth work flow. Typical work-process functions involving verbal interactions include reporting or solving problems, asking for parts, or asking for or providing help on a work process. People also talk as they hand off work to another shift or the next person in the production chain.

No participant interviewed reports being unable to meet the process-flow English demands of their current workplace. However, many say they must attend daily or weekly meetings to discuss scheduling or how to improve quality. Students in the study who attend these meetings report being somewhat "afraid" or "shy" of contributing ideas or speaking up at the meetings, for fear they will not be understood. One said, "I say something and people keep saying, 'What? What? What did you say? What?' So I stop."

Verbal interaction at work is often simply social. In areas where people have worked together a long time, participants say that everyone is like "family." Besides engaging in the usual worker verbal rituals, such as asking about a co-worker's weekend, people also discuss personal problems, vacations, ethnic recipes, and they joke together. Only three participants report that they do not talk much on the job, one who is too busy to talk, one who prefers to talk only when necessary, and one who believes it is "unpleasant for the employer when we talk on job." 
Verbal Skills and Promotion Opportunity. Several participants, including Song, whose transcript indicates that her verbal skills are the most advanced in the group (see Chapter IV, Making It Work), believe that inadequate English verbal skills are holding them back from better jobs or more opportunities on the job. Although people say they can make themselves understood on the job to assure minimal quality and complete the job, many believe they cannot advance with their current level of verbal skills.

\section{Functions of Reading and Writing at Work}

Reading on the Job. Most of the participants perform production work; their work results depend on making a high quality product, and much of their daily work requires concentration, attention to detail, and knowledge of very technical, if sometimes repetitive, processes. For products to be designed, marketed and sold, a complex organization also must be maintained through time. Within this context, reading seems to serve three main functions. First, the most frequent use of written materials is to document consistent processes, and assure quality and smooth work flow across people in the group and between groups. Second, reading functions in the workplace to transmit information needed to maintain the work organization as a social and cultural entity. Third, workers sometimes use reading as a strategy not only for learning about the particulars of their jobs, but for increasing English language skills that they believe will lead to better interaction with others, better job performance, and higher level jobs. In spite of the important function literacy serves to the success of the whole group, some individuals in the 
study in the most routine jobs say they can go through a day without reading or writing anything; most do not spend very much time reading, and less time writing in the course of a day. Table II below shows the functions of the most common literacy materials study participants encounter at work.

TABLE II

LITERACY FUNCTIONS AND MATERIALS

\begin{tabular}{|c|c|c|c|}
\hline $\begin{array}{c}\text { Process and Quality } \\
\text { Control }\end{array}$ & $\begin{array}{c}\text { Organization } \\
\text { Communication }\end{array}$ & $\begin{array}{c}\text { Learning About } \\
\text { the Job }\end{array}$ & $\begin{array}{l}\text { Language } \\
\text { Learning }\end{array}$ \\
\hline $\begin{array}{l}\text { Procedures or } \\
\text { "specs," including } \\
\text { training on process }\end{array}$ & $\begin{array}{l}\text { Memos from boss } \\
\text { about } \\
\text { organization, e.g. } \\
\text { meeting notices }\end{array}$ & $\begin{array}{l}\text { Procedures or } \\
\text { "specs" }\end{array}$ & $\begin{array}{l}\text { Bilingual } \\
\text { dictionaries } \\
\text { kept at } \\
\text { workstation }\end{array}$ \\
\hline $\begin{array}{l}\text { Memos from boss } \\
\text { or engineers about } \\
\text { changes to process }\end{array}$ & $\begin{array}{l}\text { Weekly company } \\
\text { newspaper }\end{array}$ & $\begin{array}{l}\text { Notes taken } \\
\text { down by } \\
\text { worker during } \\
\text { training } \\
\end{array}$ & $\begin{array}{l}\text { Any } \\
\text { workplace } \\
\text { document }\end{array}$ \\
\hline $\begin{array}{l}\text { Stickers affixed to } \\
\text { work describing } \\
\text { problems to be } \\
\text { fixed, rejects }\end{array}$ & $\begin{array}{l}\text { Periodic all- } \\
\text { company } \\
\text { communication } \\
\text { about benefits, } \\
\text { compensation, } \\
\text { etc. }\end{array}$ & & \\
\hline \multicolumn{4}{|l|}{$\begin{array}{l}\text { Forms tracking } \\
\text { work }\end{array}$} \\
\hline $\begin{array}{l}\text { Memos or notes to } \\
\text { and from other } \\
\text { shifts/phone } \\
\text { messages }\end{array}$ & $\begin{array}{l}\text { Occasional all- } \\
\text { employee letters } \\
\text { sent by senior } \\
\text { management }\end{array}$ & & \\
\hline Schedule Boards & Timecards & & \\
\hline $\begin{array}{l}\text { Messages on } \\
\text { computers used to } \\
\text { test or set up } \\
\text { process }\end{array}$ & $\begin{array}{l}\text { Performance } \\
\text { reviews }\end{array}$ & & \\
\hline $\begin{array}{l}\text { Parts requests-- } \\
\text { written form or E- } \\
\text { mail }\end{array}$ & & & \\
\hline
\end{tabular}


Literacy for Process and Quality Control. As Table II shows, most of the literacy materials these workers encounter function to control process or product quality. All but one of the workers must read process specifications--called by the workers "procedures" or "specs." These documents provide detailed step-by-step instructions and schematics needed for various production jobs. Written procedures are meant to assure that everyone is following the same process, thereby improving quality and efficiency. Procedures often contain charts, numbers and schematics in addition to, or in the place of, words. (Later in this chapter, some typical procedures are analyzed.) Usually, the plant provides hands-on training for new workers or for people learning entirely new product processes, but from time to time, written changes or exceptions to the procedures may be distributed. Many interviewees call these ad hoc documents "mini-routings."

To assure work flow, informal notes may also be exchanged between people in different shifts. Usually, workers receive a note only if they have not been able to come in early to talk to their cohort on the previous shift. In many areas, work flow is also assured by a common schedule "whiteboard," which outlines the number of parts or instruments that must be made for the day. These boards usually contain only instrument names or part numbers, amounts, and dates. Sometimes, there may be an alert to look out for a problem such as a defect or a process change. These written formal procedures and informal messages allow people to communicate with each other even when they cannot be in the same place at the same time, and, since 
everyone reads the same written procedures, are meant to assure consistent and accurate processes and approaches to the work.

Limited Use of Writing on the Job. In these workers' reports of their jobs, writing is most conspicuous by its absence. Several said they could get through the workday successfully without writing at all. Though many of the students interviewed feel comfortable with reading on the job, they are much less confident of their ability to do even the minimal writing required, and often come up with alternatives to do without writing (see Alternative Strategies section below). As expected, writing functions mirror reading functions on the job. The students report using writing for functions that assure process and quality, and learning on the job. Although the company often requires employees to fill out forms of various kinds for benefits programs and the like, no one mentioned this function as writing required for the job. But students do use writing occasionally to help them learn about a new job or a new aspect of their work. Several also use it to increase their English skills, for example by writing down a word heard in conversation in the workplace and taking it to ESL class to ask the teacher the meaning of the word.

The most frequently reported use of required writing on the job is a process-control function that entails filling in data sheets or forms to track work or report problems. These functions usually entail filling in part numbers, component names, and counts; this kind of routine writing varies little and requires no composition at all--the writer is essentially filling out a form. Nonetheless, students interviewed see this function as writing. For example, one of the students is responsible for 
gathering and reporting all the labor hours and exceptions for her entire group. She inputs the data into a pre-programmed computer. Another works in the stockroom and maintains records of all transactions there.

Only one person, Song, the woman who now works in the stockroom, has been required to write process specifications. In her last job in production, she was asked to write down procedures as a reference for others. She felt this task was very difficult for her, but she completed it.

Seventeen of the students interviewed also report that they need to write short notes on the job. The notes function to alert another person on the line of a problem, or to communicate work progress to another shift. They usually use small "Post-It" notes which they stick to the instrument or part; these notes move with the instrument or component to the next step in the process or to the next shift. Song reports using Email for notes to other stockrooms. One student also reports the need to write phone message notes, since she works closest to the phone. These are some typical note messages interviewees report writing:

- Note stuck to instrument and sent to next step in process: "CRT problem."

- Note left to person at another station: "I took fifteen sequences - Loan"

- Notes stuck on instrument, left for next shift: "Ready to run" and "This one everything good, but I not testing the end. Could you test, please? Next time, if then is good, you can ship."

- Note left for next shift: "All parts ready to go."

- Note left for manager: "John called in sick." 
- E-mail message to another part of the company: "I have a problem with your schedule, can you help me?"

A new type of "writing" involved in the work process is computer input for those who work on automated manufacturing or test systems and must input codes into the computer in order to bring it on line or operate it.

Literacy for Organization Communication. Employees also receive printed materials that communicate organization news, human resources processes and performance reviews. Tri-X sponsors a weekly company newspaper. The weekly newspaper is available in racks for employees to pick up. Only one of the participants says she reads it regularly; all others look at it "sometimes." Only one of the participants says reading the paper was "no problem." Others experience various levels of difficulty with it; most say they can get the overall idea, but not all the details in the articles. The study participants' favorite section of the company newspaper is the easy-to-read in-house "Trading Post," where items are listed for sale to other employees. Senior management also sends out allemployee letters to communicate company strategies, goals, problems or challenges. All of the participants receive these all-employee communications. All but one of the students have difficulty understanding correspondence from senior management; the most comprehension reported is understanding the "outline" or "basic idea" of the letters.

Performance Reviews and Timecards. Although all employees at this company fill out timecards and all receive annual written performance reviews, and many are required to write self-assessments for those reviews, only one of the students interviewed thought to 
mention performance reviews as something she is required to read on the job; only two mentioned timecards. The researcher's conversations with managers of ESL workers suggest that managers sometimes read performance reviews to workers they believe may not be able to read the review themselves. These managers believe that reading performance reviews aloud assures the worker understands the review and avoids potential embarrassment if the worker has difficulty reading the review. However, the student who identified performance reviews as a reading function on the job was asked by her manager to read the review back to him, no matter how long it took, because he wanted to see how her English classes were going. She did not regard this exercise as embarrassing or demeaning; rather, she viewed it as a demonstration of her manager's kind and patient concern about her progress.

Though employees read information about the organization, writing as means to maintain the social and cultural fabric of the work organization is rare among the students interviewed. One student mentioned that writing notes to the swing shift was important because they had to work together:

If I see a problem, the person might not be there, might be on swing shift. I write a note, "Have a problem here, please." Because we work together, so if something wrong on his instrument I let him know. Otherwise, he doesn't let me know or something like that.

One individual reports that she used to use E-mail, when she was learning it, to send notes and ask her friends to lunch. Now that the novelty has worn off, she says, she uses E-mail only for transacting business. 
Reading and Writing to Learn the Job. Process specs, procedure books, and computer programs are used not only to control work flow, but function to help train workers new to the job or retrain them when processes change. Eighteen of the individuals interviewed say they are expected to read or "look at" procedures to learn the job or to learn process changes. But, as discussed in the Alternative Strategies section below, although the work design assumes that workers will use reading as one way to learn process changes, the lower level readers in the group find other ways to fulfill the function.

Three participants with higher literacy skills (as indicated by B.E.S.T. test scores or previous education level) use writing as a mnemonic tool while learning about a new aspect of the job; they may employ strategies like jotting down words from procedures. Taking notes during job training is rare; only one person said she has used notetaking as a way to remember the training. This person believes that note-taking is something that "engineers do."

Using Reading and Writing to Learn English on the Job. Several students interviewed report using reading as a way to learn better verbal communication skills. For example, if they hear a word they do not understand at a meeting, they go to their stations afterwards and look up the word in their bilingual dictionaries. One says she sometimes reads on the job, not to complete any work function, but just to improve her reading skills.

Three participants report using writing to learn new vocabulary. Typically, these learners hear an unfamiliar word in the work environment, sound it out and write it down, spelling it as well as they 
can. They then take the word and ask a co-worker what it means, look it up in their bilingual dictionaries, or take it to ESL class to ask their teacher the meaning. Their aim is not so much to increase their literacy skills as to increase their ability to understand spoken English in the workplace.

\section{Facing New Challenges: Learning the Job}

Because the research literature so often mentions that literacy problems go unnoticed until workers change jobs or must learn something new on the job, (e.g. U.S. Department of Labor \& U.S. Department of Education, 1988), participants were asked how they approach learning something new at work. Although all but one of the students interviewed has worked at Tri-X for over ten years, three had changed jobs within the company within the last year. As expected in the highly competitive electronics business, where survival depends on introducing new products quickly and constant streamlining of manufacturing processes, all study participants report the need to learn new procedures or new products regularly.

All of the students interviewed have developed ways to learn new skills or processes; they have been able to hold their jobs during times of fast changes and severe reductions in workforce at the company. The interview results show a preferred learning approach among all the participants, though differences emerge between lower level and higher level readers. These differences entail how individuals use reading or writing to learn the job. 
Preference for Being Shown Process. Regardless of reading ability, the study participants' preferred way to learn a new job process is to have someone show it to them. For example, Vinh, who reports few reading difficulties on the job, prefers to learn a new process from the engineers who design it. He explains, "If engineer have new product, we should learn something new from them. Maybe we have meeting with engineer so engineer explain everything about the new product so we can learn." For May, the Mien woman with almost no reading skills, the preference is the same. She receives a new process specification, which indicates to her that there is a new procedure to learn, and, she says, "I don't read much. Sometime I ask the technician, sometime I ask the supervisor how to do." Interacting personally with the process expert gives the learner a chance to ask questions and get immediate clarification, or a chance to offer suggestions about how to make the process work better, as in Sook's case. She relates:

When we set up a new process, we pretty much go have meeting with engineer--with the process engineers, managers and people who wanna involve with it. We have question after question and we set up our own rules how gonna build this part ... In time, the engineer write specs. . . It's a lot easier when they come to talk to the people who's gonna do the work. Actually production people. To sit working with them instead of just talking, "Here, here's your spec, this is your drawing." Sometime, most of the time, that doesn't work that way, you know. Things doesn't work the way they predicted. So we have to kind of change the design a lot to make the order to work.

Even though one-on-one training is preferred and often available, people are held accountable for information contained in written procedures and process updates. Very limited readers, like May, Foo Lin and Paula, deal with these documents differently from the more 
proficient English readers like Fatima and Song. When the limited readers get a new process document, they always ask for help from a coworker or supervisor. In Paula's case, she may look at a sample board to try to puzzle out the new process before asking for help. She says,

We have to ask because we cannot do without asking people when go to the new place or everything different. Sometime we don't understand (the procedure) at all and we have to ask the people that work here a long time. They know what to do.

Reading and Memory. More accomplished readers try to read the procedure first, then ask co-workers to help them with words, or to show them the process once. Once the better readers are shown the process, they say that they then can "read" the process specs. When they see the words again they remember the demonstration, and then can understand the words, especially after they have done the procedure a few times.

Most participants admit that after a few times using the written procedure, they rarely use the document at all. They simply memorize the process. One reason participants give for not reading the procedures after they are familiar with the process is that they can work faster when they do not have to keep referring to the "book." As May, the non-reader, explains, limited readers are not the only ones who prefer to memorize the procedures. She says, "Sometimes, most, I remember, I'm not looking. If I remember, I not looking, I do faster. I just put this part, put it in ... It's most people, I see people, they do like that." Tina also says she only looks at procedures when the process is new or when she needs to refresh her memory:

If the new one (procedure) I don't read, I don't know what to do. But the old procedure I know what to do. But the new 
one, I have to look at every one. Another station, I know the work, but I don't work there for a while, when I come back I have to look procedure one by one. Then I remember.

Occasionally, for example if they have been away from the work for a few days, workers refresh their memories by referring back to the written procedures or drawings. Only two participants, whose work processes are very complex, said they refer to the documents often; one said she "must" use written specs in order to do the job right.

Technician Talk: Another Foreign Language. Whether they receive face-to-face verbal training or use written procedures, some of the students complain that engineers or technicians talk, and write "another language." Tou complains,

Well, sometime it's really hard and you have to ask the technician to help, because the words is just technician talk, you know? And then you have to ask "What's it mean?" I say, "Why don't you put it simple, it just makes it hard."--I mean it's not just me, American people too.

Learning from a Computer. With the advent of computer aided manufacturing, often referred to as CAM, computers serve as an alternative to paper documentation. Two of the participants said they learned their job with the aid of the computer. For example, Tou, who does instrument calibration, learned her job from a trainer and a computer. First, the trainer sat down next to her and went through the process step by step, then she read it in the computer. Now that she has completed the training she says,

If I want to do the next step, I look at the computer. I have a brand new computer next to me. When I want to, I push the button and it teach me what to do. I remember then, and if I don't remember I have a little book, I put it in Thai or in English and then I open it and then I do it. 


\section{Alternative Strategies for Accomplishing Literacy Functions}

The students in this study demonstrate a range of literacy skills. By their own assessment, however, no one can read or write everything that they encounter on the job. Most have developed alternative strategies to accomplish the functions of process and quality control, organization communication, and learning new aspects of their jobs.

Asking for Help. When workers interviewed encounter a situation that requires reading or writing beyond their ability, their most common approach is simply to ask for help. Helpers may provide literacy assistance, such as the spelling of a word for a note, or may help accomplish the task without use of literacy, such as showing the ESL worker how to do a new procedure.

Since most people in this study work with no one who speaks their native language, asking for help requires English verbal skills, as well as good relationships with the helpers. Most often, but not always, study participants choose helpers who work in close physical proximity with them, and are people they know well. These are usually workers at the same job level or status in the organization, but may also be supervisors, or technicians or engineers who have needed information. Some of the participants say they "ask anybody" for help, while others have established regular literacy helpers. Usually, managers above the person's supervisor are asked for help only on very important matters.

Kim, for example, says she usually asks an "American lady," explaining,

I do read but not understand the whole thing (process spec) so some of 'em then I usually go ask what the meaning ... we always help each other. We don't pick (on) each other, 
especially language-wise, you know. English we always ask each other. Sometimes person (the lady she usually asks) absent, I just call neighbor next door, I call somebody come, I ask.

Fatima, who is relatively new on her current job, casts a wide net for help when she needs to write a note to the second shift:

Oh, I am open. I'll call everybody. Anybody I call, "Please, engineer, write this, I cannot write this." Because something unfinished, I have to finish. I have to write now, (but ) I can't, (because I have to go to) classroom. I did unfinished job there, I should explain second person coming in, swing shift coming in.

Another important criteria for choosing who to ask for help seems to be expertise or experience with the problem to be solved, rather than just literacy expertise. Study participants are very concerned with achieving quality results; they do not want to compromise quality simply because they encounter a difficult literacy task. For example, Haing, who works with dyes, explains:

Well, some of the people will give you a bad look. But I ask whoever will come to answer me. Some people don't like to answer me, I don't ask. . . . Sometime, some word I don't understand. Because my job very important if you don't understand you don't do it because if you wrong is a lot of money. The dye is cost a lot of money, one part sometime two, three thousand. One small part like that. Have to be very careful. I never make any mistake at all. . . if I am not sure, I don't do it. I wait until whoever know how to do that comes and then I ask. I don't take a chance by myself.

Most of the time, interviewees say, they encounter no problems asking for help because they have long-standing and close relationships with their co-workers. Only three people interviewed, all women, cited occasions where co-workers refused to help or made disparaging remarks in response to a request for help. Two of the women quickly learned who to ask, and simply avoid approaching uncooperative helpers again, but 
only one, Haing, has become wary of asking any questions or revealing she cannot accomplish literacy tasks.

As discussed in the Facing New Challenges section above, participants' preferred type of help, even among those who can read most of what they encounter at work, is to have the procedure or process shown to them. Not only does a demonstration help the individual understand how to do the process, it also seems to contribute to reading comprehension. Mimi explains her approach to a new spec:

First thing, I dunno, I guess something brand new they give you the paper, right? You gotta look it over and then they can show you after that. If that piece of paper sometime doesn't make no sense you don't understand. I mean, you can read some things, but make no sense to you. But you know what is happen after they show you how it come back together--oh, it makes sense.

Selective Scanning. Some participants report scanning for part numbers only, or looking only for "what's new" when they receive a new procedure or "mini-routing." Sook, for example, looks at the specs every day because sometimes engineers update them without telling the group. She explains:

It's pretty much the same job every day. But engineer change different, let's say different step. But it's the samesame we used to do. That's the reason you should be reading every day. Because they updating the specs without telling the group. That's why it's very important even though you don't know how to read, you just go through, and if anything different make sure you ask somebody. I trying to read as much as I can. If something is different I will not start the job until I ask somebody.

Memory and Job Aids. As evidenced in the section Learning New Challenges above, many people rely on memory to learn a job, only using 
documentation to jog their memory. Some people rely on other aids to help remember job processes.

Students interviewed sometimes use what Sticht (1981) has called "job aids," often in very innovative ways, to help them learn or remember something on the job. These job aids do not rely on reading or writing skills. One student believes that the sample board provided by the manager helps her learn much more effectively than written procedures; she just looks at it and makes a circuit board to match. Other students prefer process maps or schematics to written procedures. Foo Lin says, "I cannot read but I can remember, and if the procedure have picture is a lot better."

As described in the vignettes, May, the Mien woman, has devised a memory aid that might best be described as creating a sign for herself . If May must write a note describing a bad part, she asks a co-worker how to write the problem down. She copies what her co-worker writes onto a piece of sticky note paper, and sticks the paper by the bin containing the type of parts that experienced problems. When May encounters the same problem with that part again, she simply copies down the note and sticks it to the faulty part. Though by her own assessment she cannot write English, she has devised a strategy for accomplishing literacy functions without learning how to write or decode the words in the note.

Listening to Read. From time to time, employees receive letters from the company about events, results, or benefits. Some may be important, others not. Although many of the students interviewed say they have difficulty reading the letters, one has devised a way of ascertaining if they are important enough to require help. When a letter 
comes from the CEO, say, she simply watches and listens to her coworkers during the day and at lunch. If their conversations indicate that something new or important was contained in the letter, she asks someone to tell her about it.

Avoidance Strategy. One way to cope with literacy demands that are too difficult is to avoid them. One student reports that though she usually asks for help with procedures, if she encounters parts she cannot read, sometimes she just "skips it." Haing reports that although before she began attending ESL class she would do anything to avoid having to write, she still accomplished the writing function:

I know how to talk but I don't know how to write at all because I'm afraid I'm gonna write wrong at work, you know. If something I need to write, I don't write, I straight to that person and talk to them.

Another participant uses avoidance in another way. She says that although she can read and write what she needs to on her current job, she would like a better job. However, she avoids applying for jobs that she thinks require reading and writing above her level.

Bilingual Strategies: Dictionaries and Home Helpers. If workers interviewed choose not to ask co-workers for help, they may use dictionaries, get literacy help from home, or ask teachers. Several people interviewed, all literate in their native languages, keep a bilingual dictionary at their workstations. These people may try to decode a document before asking for help, especially if no one is immediately available. Fatima, who does not hesitate to ask friends for help, keeps her dictionary handy, "Mostly I ask American friends," she explains. "They know better, I am sure they know. Or I have my dictionary with 
me and I look that if I have questions." But Fatima, like others, also takes home the most difficult documents, usually memos or documents that function to communicate about the organization. At home, relatives with more advanced English literacy skills can help. Fatima says,

When I read things generally I get some idea what's going on. Not all. Then for sure I ask my manager explain what this is, or I can go home my husband explain. "I have homework for you," I tell him. He read for me what's going on. I like to read Tri-X Weekly News. I like to understand what's going on in the company. I don't understand, I ask. Plus my husband at home.

\section{Extended Networks: Literacy at Home}

All participants were asked how they use English reading and writing at home. Three, Paula, May and Yung, report reading no English at home.

Most study participants who read some English at home do so to "learn English." Common sources of reading material are children's or siblings' school books. Tina, for example, has a daughter in seventh grade; Tina finds she is able to read the material, and finds it interesting. Tou, the woman from Thailand who claims she learned English from soap operas, subscribes to Enquirer, Star and House and Garden, which she reads for relaxation as well as to learn English. Fatima said she likes to read easy books with interesting topics and "big print," but has a hard time finding materials. The women especially report having little time to do any reading or writing at home due to the homemaking responsibilities. Many have husbands who conduct most of the family business, including business involving literacy transactions. 
All participants but Song and Vinh use writing at home almost exclusively as a tool for learning more English, except to pay bills. Participants practice writing at home, do homework, or occasionally write down words they see in written materials to bring back to the English class to get help. Children and spouses are other sources of teaching; three students report working with their husbands or children regularly to learn English. Song and Vinh are both literacy resources for their Asian friends. Song sometimes writes letters for her friends, and Vinh helps people write letters and fill out forms, such as government forms. The Value of Learning: Why Participants Attend ESL Class. Although the study interview guides do not include specific questions about ESL instruction, many participants talk about learning English, their reasons for attending class and the role of the Workplace ESL class they were attending. Many interviewees who discuss learning English or coming to English class talk not so much about improving or coping in their current job, but about getting ready for the future. Nonetheless, most feel that the Workplace ESL class has helped them communicate in their current jobs.

Vinh talks about how English would help him improve his career:

I think English very important if I want to improve my life, my career, so I should have good talk, good writing so maybe I understand Americans say or maybe American understand what I say so maybe I look for a higher job.

Tou also speaks about English in terms of her aspirations for the future:

I would like to improve my English. I would like to learn to read and write better. I really want to because I would like 
to have a better job and do different things for the future. I think I like to open my own business.

Mimi does not think reading on the job is difficult now, but she anticipates it will become more difficult, and wants to be ready. She says, "It's not hard yet. It will be in the future. That's why I need English class."

Kim, a 39 year old Korean woman, is attending English class at the urging of her manager, who told her that his own group had no problem understanding her, but that she might have a problem outside her group. She explains, "My boss suggested it (ESL class) a long time ago. He says inside group, no problem, but maybe outside group a problem. I never go, but this time I made up my mind I need to go learn before I get old."

Several participants perceive their major impediment to better English to be "spelling." Below are some of their comments about English and spelling:

Paula: I really like read and spell. I really try very hard you know but I'm never been to school before. I hope I can spell soon.

May: I want to learn reading and writing, but any kind I want to read. And sometime I can say the name, but I don't know how to spell it--it's hard to for me to spell it.

Mimi: I have problem most spelling. I have problem reading, but spelling worst. You can read the sentences but I cannot spelling very well. I need, I really need a lot to study English.

All students interviewed who discuss English class believe that it has helped them make improvements in English at work. It has especially boosted their confidence to speak up, ask for help, or write things they wouldn't have tried before. Since many participants' jobs 
demand minimal writing, and they read or write very little English at home, English class may be the only place they practice writing. Haing, the Cambodian woman with three years previous education, sums up how the Workplace ESL class has helped her:

It help me a lot to writing. Because I know how to talk but I don't know, I don't want to write at all because I'm afraid. I something need to write, I don't write, I straight to that person and talk to them. Now since I come to ESL class, I learn how to write some easy word and I try and I say the person, "If I do wrong, please correct me." I like to know how to read, that's all I can say. I come to learn English more, because at work is not like learning English because just work, only working.

The remainder of this chapter discusses results of the B.E.S.T. test, taken by nine participants, and an analysis of some typical workplace documents.

\section{B.E.S.T. TEST RESULTS}

\section{Unexpected Results}

Teachers of the Workplace ESL classes administered the literacy section of the B.E.S.T. tests during class time. On the day the test was administered, nine study participants attended class. After administering the test, teachers noted that some students, especially those at lower levels, were extremely nervous and upset by the test. The company was going through layoffs at the time, and though teachers assured them otherwise, some students feared test results might be used against them. Since the B.E.S.T. literacy test asked for personal information such as name, age, and country of origin, students felt they could be identified. To protect the study subjects, and assure 
cooperation with the interview process, B.E.S.T. testing was discontinued (see Study Limitations, Chapter VI).

\section{Test Results}

Table III shows the test scores of the nine students tested. Students are listed by alias (see Table I, Demographic Summary). Next to the test score, the B.E.S.T. Student Performance Level for that score is displayed. Student Performance Level descriptions are taken from the B.E.S.T. test administration manual (1984, p. 51). Each student's number of years of education before coming to the United States is also listed.

All those tested were able to complete personal background information, write a check, and determine prices from tags on the test. B.E.S.T. Test Student Performance Level correlations (see Table III) corroborate this result.

Test Results and Previous Education. Vinh and Fatima, the students with the greatest number of years of education in their native country, achieved the two highest scores; Haing and May, who have 3 years or less of previous education, scored the lowest. However, Tou, with four years of education, scored in the same Student Performance Level as $\mathrm{Li}$, who has 12 years of education. Although previous education appears to be related to achievement on the B.E.S.T., not enough statistical data is available from nine subjects to draw any reliable conclusions.

B.E.S.T. Scores and Interview Results. Information from interviews shows differences in how participants with different test scores approach 
TABLE III

B.E.S.T. TEST SCORES, STUDENT PERFORMANCE LEVELS (SPL), YEARS PREVIOUS EDUCATION

\begin{tabular}{|l|c|c|l|l|}
\hline Student & $\begin{array}{c}\text { Test Score/ } \\
\text { SPL }\end{array}$ & $\begin{array}{c}\text { Years } \\
\text { Previous } \\
\text { Education }\end{array}$ & \multicolumn{1}{|c|}{ SPL Description Reading } & SPL Description Writing \\
\hline Vinh & $66 /$ VII & 17 & $\begin{array}{l}\text { Reads with partial understanding } \\
\text { some non-simplified materials on } \\
\text { everyday subjects. }\end{array}$ & $\begin{array}{l}\text { Performs routine writing } \\
\text { tasks within familiar } \\
\text { contexts with some errors. }\end{array}$ \\
\hline May & $35 /$ III & 0 & $\begin{array}{l}\text { Reads and understands some } \\
\text { common sight words and simple } \\
\text { learned phrases related to } \\
\text { immediate needs. }\end{array}$ & $\begin{array}{l}\text { Writes some very common } \\
\text { sight words and basic } \\
\text { personal information with } \\
\text { help. }\end{array}$ \\
\hline Tou & $49 / \mathrm{V}$ & 4 & $\begin{array}{l}\text { Reads and understands short, } \\
\text { simplified materials related to } \\
\text { basic needs; some } \\
\text { misinterpretation. }\end{array}$ & $\begin{array}{l}\text { Writes phrases and some } \\
\text { short, simple sentences with } \\
\text { some errors. }\end{array}$ \\
\hline Li & $51 / \mathrm{V}$ & 12 & $\begin{array}{l}\text { Reads and understands short, } \\
\text { simplified materials related to } \\
\text { basic needs; some } \\
\text { misinterpretation. }\end{array}$ & $\begin{array}{l}\text { Writes phrases and some } \\
\text { short, simple sentences with } \\
\text { some errors. }\end{array}$ \\
\hline Haing & $42 / \mathrm{IV}$ & 3 & $\begin{array}{l}\text { Reads and understands simple } \\
\text { learned sentences, and some new } \\
\text { ones, related to immediate needs; } \\
\text { frequent misinterpretation. }\end{array}$ & $\begin{array}{l}\text { Writes common words and } \\
\text { simple phrases related to } \\
\text { immediate needs with } \\
\text { frequent errors. }\end{array}$ \\
\hline
\end{tabular}


TABLE III

B.E.S.T. TEST SCORES, STUDENT PERFORMANCE LEVELS (SPL), YEARS PREVIOUS EDUCATION (continued)

\begin{tabular}{|c|c|c|l|l|}
\hline Student & $\begin{array}{c}\text { Test Score/ } \\
\text { SPL }\end{array}$ & $\begin{array}{c}\text { Years } \\
\text { Previous } \\
\text { Education }\end{array}$ & \multicolumn{1}{|c|}{ SPL Description Reading } & SPL Description Writing \\
\hline Loan & $57 / \mathrm{VI}$ & 12 & $\begin{array}{l}\text { Reads and understands simplified } \\
\text { materials on familiar subjects; } \\
\text { attempts some non-simplified } \\
\text { materials, but needs a lot of help. }\end{array}$ & $\begin{array}{l}\text { Performs basic writing tasks } \\
\text { in a familiar context with } \\
\text { some errors. }\end{array}$ \\
\hline Fatima & $64 / \mathrm{VI}$ & 17 & $\begin{array}{l}\text { Reads and understands simplified } \\
\text { materials on familiar subjects; } \\
\text { attempts some non-simplified } \\
\text { materials, but needs a lot of help. }\end{array}$ & $\begin{array}{l}\text { Performs basic writing tasks } \\
\text { in a familiar context with } \\
\text { some errors. }\end{array}$ \\
\hline Tuan & $61 / \mathrm{VI}$ & 9 & $\begin{array}{l}\text { Reads and understands simplified } \\
\text { materials on familiar subjects; } \\
\text { attempts some non-simplified } \\
\text { materials, but needs a lot of help. }\end{array}$ & $\begin{array}{l}\text { Performs basic writing tasks } \\
\text { in a familiar context with } \\
\text { some errors. }\end{array}$ \\
\hline Sook & $45 / \mathrm{IV}$ & $\begin{array}{l}\text { n/a (less } \\
\text { than 6) }\end{array}$ & $\begin{array}{l}\text { Reads and understands simple } \\
\text { learned sentences, and some new } \\
\text { ones, related to immediate needs; } \\
\text { frequent misinterpretation. }\end{array}$ & $\begin{array}{l}\text { Writes common words and } \\
\text { simple phrases related to } \\
\text { immediate needs with } \\
\text { frequent errors. }\end{array}$ \\
\hline
\end{tabular}


literacy functions. Vinh and Fatima, the highest scorers, read to supplement training and even go beyond the expectations of their job to read about the theory behind their work processes. Loan and Tou, with slightly lower scores, can understand some of the reading on the job, but also ask for help in reading. Haing and May, who demonstrate the least literacy proficiency on the B.E.S.T. test, ask for help often. They like to be shown a process, rather than receiving help with words or reading. Both Haing and May rely on memory and help from others to achieve literacy functions. These findings suggest that participants with higher literacy skills, though they may also prefer to learn by watching, can use their literacy skills as an added strategy for work success; literacy is one more tool in their survival kit. Below are interview data on literacy use and learning for students with a range of B.E.S.T. test scores:

Vinh-Score 66:

Vinh says, "If we have a new instrument, we should read about it, always learn." He reports being able to read and write on the job with no problem. When Vinh does not understand a process on the job, he goes back to the book and reviews the information.

Fatima - Score 64:

Fatima reports no problems with reading, but sometimes needs help writing. She uses a manual to learn how to operate her machine, although she prefers to receive handson training as well, and then reads about the operation. She reads to learn about some of the electronic theory behind her work processes.

Loan - Score 57:

Loan says that she can read the procedures sometimes, sometimes not. When she doesn't understand, she asks for help. She says that in general, she can understand most of the memos that her boss circulates without help. 


\section{Tou - Score 49:}

Tou believes she can read better than she can write, and says "I understand better than I can read." Once a trainer shows her how to do a process, she can read most of the documentation, but she likes to be shown first. Generally, she learns by listening and watching, and "some reading."

\section{Haing - Score 42:}

Haing can read some of the procedures she gets, but says she cannot read them if they contain "hard words." She says she usually works from previous knowledge and memory, and can "read" the procedures mostly because she performs the process they describe all the time, so she knows what they say.

May - Score 35:

May can easily follow a schematic map of a process, but has great difficulty understanding written procedures. She doesn't use procedures when she can avoid it, preferring to commit the work process to memory. May asks for help on most other literacy tasks.

\section{RESULTS OF DOCUMENT ANALYSIS}

Research question one asked what level of reading and writing skill typical workplace literacy functions assume. To answer this question, four types of documents were analyzed for readability. Pertinent interview comments related to the documents were also analyzed.

\section{Process Specifications}

Three sample process specifications from an area where several students work were analyzed. Because process specifications contain manufacturing information sometimes considered trade secrets, they are highly confidential. The content analysis is therefore discussed in 
general terms, though each process specification describes a different process, authored by different designers.

What Study Participants Say About Process Specifications. As discussed in the previous section, Interview Results, every person interviewed works with process specifications, sometimes also called "specs" or procedures, which describe how to perform discrete steps of the manufacturing process. They report that they are always expected to follow the specifications. Many participants memorize specifications, only referring to the written document when a change has been made to the process, or when they are learning a new process. Some study participants with very complex or fast-changing jobs say they refer to the documents throughout the work day.

Study participants report varying levels of success in reading process specifications. While some, like Song, read procedures with little difficulty, others like May or Foo Lin can read only parts. Lower level readers say that the illustrations and "numbers" in the documents help them understand better. Even higher level readers in the group complain that specifications are sometimes written in "engineer language" that the participants do not understand and cannot read because of specialized jargon and a writing style that is difficult to read.

Fry Readability Analysis. Each process document was analyzed for readability using the Fry readability scale, as described in Chapter III, Methods. Guidelines for conducting the Fry Readability Analysis are included in Appendix D. Readability ranged from sixth grade to tenth grade level. Scores for all documents analyzed are summarized in Table IV. 
TABLE IV

SELECTED DOCUMENT READABILITY BASED ON FRY SCALE

\begin{tabular}{|l|c|c|c|}
\hline \multicolumn{1}{|c|}{ Document } & $\begin{array}{c}\text { Avg. No. of } \\
\text { Syllables per } \\
100 \text { Words }\end{array}$ & $\begin{array}{c}\text { Avg. No. of } \\
\text { Sentences per } \\
100 \text { Words }\end{array}$ & Grade Level \\
\hline Process Spec 1 & 140 & $\begin{array}{c}5.5^{*} \\
4.8^{* *}\end{array}$ & $\begin{array}{c}8^{*} \\
8^{* *}\end{array}$ \\
\hline Process Spec 2 & 144 & 10.3 & 6 \\
\hline Process Spec 3 & 159 & 7.3 & 10 \\
\hline Tri-X Weekly News 1 & 159 & 4.7 & $11-12$ \\
\hline Tri-X Weekly News 2 & 169 & 4.9 & 14 \\
\hline Tri-X Weekly News 3 & 175 & 5.4 & $15-16$ \\
\hline $\begin{array}{l}\text { Tri-X Weekly News } \\
\text { "Trading Post" }\end{array}$ & 209.3 & 20.6 & $\mathrm{X}$ \\
\hline Benefits Workbook & 169 & 6.5 & 15 \\
\hline Letter 1 from CEO & 200 & 4.1 & $17+$ \\
\hline Letter 2 from CEO & 164 & 6.1 & 11 \\
\hline
\end{tabular}

$\mathrm{X}=$ Not Scaled

* = If paragraph headers are counted as one sentence

** = If paragraph headers are not counted as one sentence

The Fry readability guidelines (Fry, 1978) were difficult to apply in several sections of the process specifications, such as sections including lists, tables of numbers, and outlines. Items on one line of a list were counted as one sentence, as were subject headers.

Other Readability Factors. Since different designers write their own procedures, the style of the procedures analyzed varies, although the numbering of sections follows a strict standard. For example, one 
author lists steps or sub-points one by one in a column, while another strings steps into a paragraph. Except for sections of the procedures outlining step-by-step processes, the procedures tend to contain a high number of passive sentences. Even step-by-step instructions, however, sometimes slip into passive voice, for example, "Cure must not be done in the same oven as other parts," or "the oven should not be opened during cycle."

Vocabulary in the procedures is by necessity technical. Idioms and vocabulary specific to the manufacturing process often appear as well. One of the documents shows a tendency toward the choice of multisyllabic words rather than shorter synonyms. Several misuses of words, misspellings, and typing errors also appear in one of the documents. Two of the three procedures contain supporting illustrations and/or graphs.

\section{Tri-X Weekly News}

The Tri-X Weekly News is published every Friday; enough copies are distributed in company buildings for all employees to take. Along with quarterly live video broadcasts and employee meetings, it is the main vehicle for distributing news about the company to employees.

Each issue of Tri-X Weekly News analyzed contains three to four in-depth news articles about the company. In the three issues analyzed, news items covered such topics as an interview with a division vice president discussing strategic direction, an all-employee memo from the new president discussing business challenges, an article about honors received from a major customer, an article on reasons for field office 
consolidation, an article about the ISO 9000 quality certification process, and an article about how the company's products can be applied to automotive repair. In addition to these in-depth articles, each issue contains announcements intended to reach all employees, such as United Way deadlines, new holiday dates, an update on an employee loan program, and upcoming classes. Every issue contains birth and death announcements. Every other issue contains a section called "Trading Post," where employees can list items wanted or for sale. In addition, each issue contains a Questions and Answers section, where employees can send questions about the company to be answered.

Fry Readability Analysis. The December 4 issue of the Tri-X Weekly News is written at an 11th to 12th grade level on the Fry scale, the January 8 th issue is at a 14th grade level, and the January 15th issue at grade 15 to 16 . See Table 4 for Fry Readability summary.

Since it is organized and written very differently from other parts of the Tri-X Weekly News, the "Trading Post" section was analyzed separately. Using the Fry approach, each number must be counted as a syllable. The "Trading Post" contains an average of 209.3 syllables and 20.6 sentences per hundred words. No Fry readability grade level is available for this ratio of sentences and syllables. See Table IV for a summary of Fry Readability results.

Benefits Workbook

Once a year, at benefits-enrollment time, employees receive a Benefits Workbook that provides details of the company benefits programs. 
Fry Readability Analysis. The three sections of the workbook chosen at random yielded a Fry readability of grade 15. However, much information in the workbook is available in three forms: summary sections, detailed sections, and easy-to-read tables or graphs.

Other Readability Factors. Clearly, an effort has been made to make the workbook readable and easy to use. Each of the content areas in Section I, such as "Medical Benefits," begins with a Table of Contents for that section. Each content area includes a section entitled "Key Words," which defines technical terms used in that section. The Benefits Workbook uses many tables and charts to clarify, summarize, or give examples.

\section{Letters from Management}

The first letter analyzed is one page long and discusses the company's commitment to the practice of providing opportunities for minority-owned vendors. The overall tone of the letter can be described as very legalistic. The second letter contains two pages, describing in detail a business situation in which investors with unknown intentions are asking for seats on the Board of Directors.

As previously mentioned, participants interviewed find letters from senior management difficult to read, and generally get help with them. They may take the letter home to get help from a family member, ask their manager, or ask a co-worker what the letter says.

Fry Readability Analysis. The first letter analyzed is written at grade 17 on the Fry scale; the second at grade 11 . Based on the 
interview and B.E.S.T. test results, both of these letters would be too difficult for study participants to read. 


\section{CHAPTER VI}

\section{DISCUSSION}

This study began with three research questions:

1. For what functions are reading and writing actually used in the workplace? What level of reading and writing do these functions assume?

2. How do these literacy functions relate to the rest of the work system? For example, to what extent are these functions related to individual job performance, success of the group, and success of the organization?

3. How do limited readers--or the group as a whole--fulfill these literacy functions? Specifically,

a. What kinds of individual reading or writing skills and strategies or techniques do they apply to the literacy function?

b. What kinds of relationships or social networks, if any, do limited readers make use of to fulfill literacy functions?

c. Do work teams "share" or specialize in literacy functions? If so, how?

d. If individuals or groups do not use their own literacy skills to fulfill literacy functions, what alternative approaches do they apply?

e. How can we leverage what we discover about the strategies limited readers use in the workplace to enhance 
workplace ESL, job training, and employee communications programs?

This chapter discusses questions 1 through $3 \mathrm{~d}$. The chapter also includes a discussion on study limitations. Question 3e, which involves implications for the workplace and workplace ESL programs, is addressed in Chapter VII.

The results of this study were presented to a group of ten manufacturing and process engineering managers in a Tri-X plant where many of the participants work. Where applicable, their comments are included in this discussion.

\section{QUESTION ONE: FUNCTIONS OF LITERACY IN THE WORKPLACE}

\section{Process Documentation}

The major function of literacy in the workplace studied is to establish and maintain work processes. Literacy materials such as process specifications, "mini-routings," notes between workers, and schedule boards assure smooth process flow and quality. They are also key goals of the manufacturing function. This study suggests that when production workers think of literacy on the job, they think of it primarily in terms of process functions, including learning a work process.

The second part of Question One asks what level of reading or writing proficiency literacy functions assume. Document analysis shows that process reading materials are written at about an eighth grade to tenth grade reading level. However, managers say that they do not in fact assume that everyone can read all process specifications or related materials such as safety cautions; managers have devised some 
alternative ways to inform or teach people such as hands-on training or verbal instruction. What is important to the managers is that the function be accomplished in the most efficient and accurate way possible; reading the documents is assumed to be the easiest way to accomplish the process function, but not the only way.

Even though hands-on training is available for new workers or entirely new processes, workers are held accountable for mini-routings, the short written updates disseminated about process changes. Workers are also expected to understand and write short notes attached to products or left for them from other shifts.

\section{Organization Communication}

From the employer's point of view, another important function of literacy at work is employee communication about the organization. Study participants receive all-employee communications but do not always make sure they understand them. For example, they seldom read Tri-X Weekly News or ask for help reading it.

Document analyses and interview results clearly show that Tri-X employee communications documents assume at least a high school reading level. They are written at levels beyond the reading skills of most of the ESL workers in this study. Unlike the managers who work with these production workers every day, corporate managers responsible for disseminating information in Tri-X Weekly News, CEO letters, or benefits communications assume that these materials will be read. 


\section{Literacy to Learn English on the Job}

A less common function of literacy in the workplace is using reading and writing to learn English. Study subjects use reading and writing as ways to learn new words or grammar, both job-related and unrelated to the job. This function of literacy differs from process communication and organization communication in that it is a function some ESL participants add to their jobs, not a function required by the employer.

\section{QUESTION TWO: HOW LITERACY FUNCTIONS RELATE} TO THE WORK SYSTEM

\section{Literacy Processes, Work Process Design, and Quality}

To compete in the 1990s, companies are increasingly turning to Total Quality Management (TQM). A key component of most TQM models is process improvement, achieved through painstaking analysis of work processes, and elimination of unnecessary steps or redesign of the process (Rummler \& Brache, 1990). To be able to compete in global markets, many companies including Tri-X are seeking certification in an international quality standard named ISO 9000. ISO 9000 certification requires detailed documentation of all work processes, and requires that workers be able to perform tasks outlined in these processes. Given this scenario, process documentation is becoming more, rather than less, important to a worker's job. This study has shown that a key function served by literacy on the job is assuring process flow and quality. This function is crucial to the entire work system because it can affect the quality of products produced and the cost of producing them. 
How are literacy functions related to individual job performance? To achieve high performance on the job a worker must fulfill job literacy functions. However, the ability to read literacy materials by oneself, using personal reading and writing skills, is not the only way that literacy functions can be accomplished. As the interview results and vignettes show, workers apply many alternative strategies to successfully accomplish the major literacy functions of quality and process flow.

Not being able to read at expected levels does seem to put a worker at greater risk of making an error or missing some important manufacturing process change or company communication. Lack of literacy skill also limits new workers, who have not established alternative strategies or networks to help them accomplish literacy functions.

Figure 1 maps the processes study participants typically use to learn a new procedure or process change. The figure shows how individual literacy skills and alternative literacy networks and strategies function together within the work system. In this system, there are many paths to success, but as the figure shows, some are more complex than others. A number of factors interact to determine which path is chosen, including individual literacy skills, ability to ask questions, availability of helpers, workers' understanding of the process, availability of training, and a well-designed procedure that works. A few examples illustrate these interactions.

Red Path: Proficient Readers with Work Experience. An engineer makes a modification to a process, writes and circulates a mini-routing 


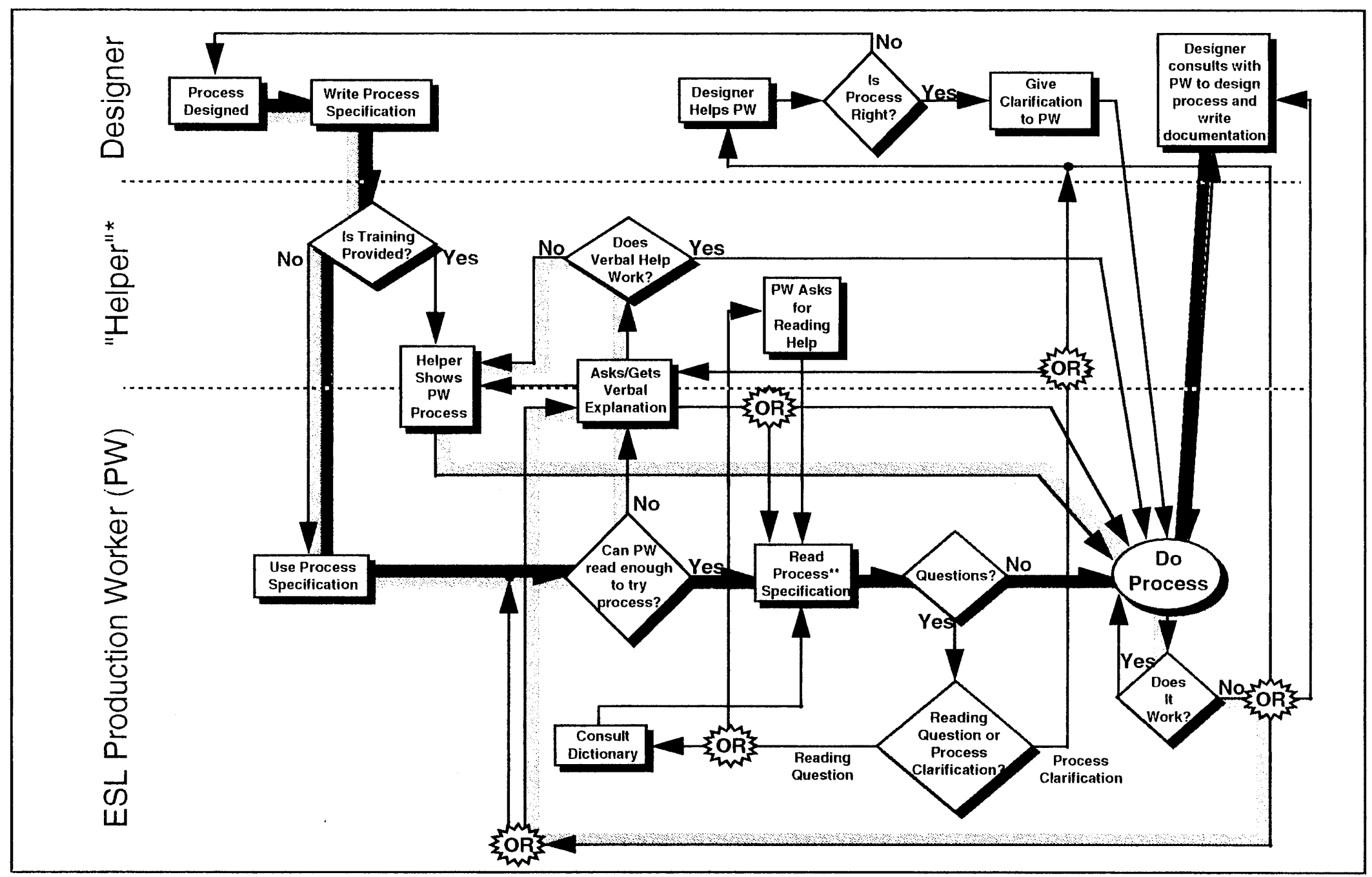

Figure 1. Learning Map for Manufacturing Process 
directly to the assemblers. No training is provided; the production worker is familiar with the underlying process and able to read the minirouting, follows the process described in the mini-routing and successfully performs it. This path requires little verbal interaction if the workers can read, the process is well designed and works, and the worker needs no process clarification.

Light Blue Path: Non-Reader. A new procedure is given to a nonreader with limited English verbal skills. No training is provided. The non-reader asks someone to explain the process to her, but does not understand the explanation, so must have someone show her the process. She tries the process; it doesn't work, so she goes back to a helper for further clarification until the process works.

Yellow Path: Reader or Non-Reader with Hands-On Training. The manufacturing process is designed. Hands-on training is provided. The worker performs process. Little or no reading is required.

Green Path: Designer-Production Worker Collaboration. Designer and assembler work together to design the work process and write documentation. The worker, having contributed to the design, is able to do process; questions are minimized.

As this figure shows, there are many other possible paths on the way to learning a new work process, depending on how the work flow is designed, who works together, and whether a worker asks reading questions or process questions. The learning map illustrates that without literacy skills or close hands-on training, workers must communicate verbally in English. Without English verbal skills, they must have excellent reading skills. Even if reading skills allow the 
worker to follow a written process, if the process itself is poorly designed or written, verbal skills will be required for clarification.

Figure 1 also illustrates the importance of hands-on training, and the potential efficiencies in having ESL production workers and process designers team up to design processes. If the design engineer and ESL production worker collaborate on the design process and documentation, there is a much better chance that the manufacturing process will work the first time, and that the worker will be able to perform the task. Interview results also suggest that collaborating in the design process makes it easier for workers to read the process documentation, since they bring knowledge of the process itself to the literacy task.

\section{Organization Communication and Marginalization}

Limited readers do not read many company-wide employee communications, which may put them at greater risk of becoming more marginal members of the social system of the company. Interview results clearly show that limited readers receive fewer promotional opportunities. It is unclear whether this limitation is due to actual job performance, marginalization from the company culture due to insufficient company information or cultural differences, or managers' perceptions that new jobs require higher literacy skills than the worker can handle. 
QUESTION THREE: HOW LIMITED READERS

FULFILL LITERACY FUNCTIONS

Individual Reading and Writing Skills and Strategies Applied to the Literacy Function

This study group demonstrates a range of abilities in reading and writing English. Generally, those who are proficient readers will begin by trying to read workplace literacy materials to accomplish the literacy function. However, even the most proficient readers supplement the written materials with questions to co-workers, either for help with the reading or clarification of the information contained in it. Workers also choose not to read certain documentation once they have committed a process to memory; after a process is memorized, they read only to refresh their memories if they have been away from the work. Some workers do not apply reading skills at all, preferring other alternatives to learn a job task.

Both proficient readers and more limited readers apply scanning skills to new reading material. They look for what is important to them, whether it be a change in a work process, the classified ads in the company newspaper, or a new English word. What is important is determined by their own values and by the expectations set by management. For example, Tri-X has been instilling quality as a corporate value for many years; workers performance reviews and pay raises often depend on their quality levels. Many of the participants take care to read process specifications or management memos carefully because they know that the information may affect quality. However, very few read Tri-X Weekly News, since they see little immediate value to 
them. ESL workers will try to glean information from letters from the CEO, or get help reading them, because the status of the writer is recognized and valued.

\section{Relationships or Social Networks Used to Fulfill Literacy Functions}

At the beginning of this study, it was noted that individuals often accomplish literacy functions far beyond their individual ability to decode the literacy materials. It was suggested that one way individuals are able to accomplish these functions is to use social networks and relationships. The results of this study show that people can be "functionally literate" in their workplace--that is, they can accomplish many literacy functions--without being able to read beyond a very minimal level. To do so requires using social networks and interpersonal relationships extensively.

ESL production workers in this study rely on literacy help networks. Helpers may include a wide range of people, or be limited to a single person. In most cases, helpers work close by the ESL worker, although sometimes individuals walk some distance from their workstations to get help. Regular helpers usually occupy the same social status in the company, but higher-status individuals may be sought out for help occasionally. What is required of a helper is proficiency in English literacy, and, if possible, expertise in the information to be read or written. The participants in this study who have the longest established reciprocal working relationships--the "family" relationships-appear to experience the fewest difficulties accomplishing literacy functions. The few workers in the study who are newer to the job, or are 
experiencing interpersonal or cultural conflicts, have more difficulties receiving help and accomplishing literacy functions. All helping relationships rely on good verbal communication, which depends on English proficiency (if the helper is an English speaker) and interpersonal relationships.

This study did not specifically focus on the role of cultural bias or intercultural communication in functional literacy. Given the importance of social networks to limited readers' ability to accomplish literacy functions, cultural issues may play an important role, as suggested by the interview with Haing, who feels she encounters cultural bias on the job. The role of cultural bias in functional literacy deserves further research.

Workplace literacy networks extend beyond the workplace to the classroom and the home. People use relatives and friends with stronger literacy or English skills to help them understand materials such as employee benefits workbooks, or letters from management. The more difficult the reading material, the more likely study participants are to bring it to ESL class or home to get help.

\section{Other Alternatives: Bypassing Literacy}

Helping relationships and literacy networks are an important way ESL workers with limited literacy skills accomplish literacy functions. Another common strategy is to bypass reading and writing altogether. and convey or receive information another way. The most common way to bypass literacy is to watch the process being done, practice, and memorize it. Even study participants with higher levels of reading 
proficiency sometimes prefer watching and practicing a process to reading about it. Pictures, models, or schematics are often preferred over written "how to" step-by-step process descriptions.

In the case of process documentation, such as new procedures or mini-routings, if workers choose not to use the written document, they always find out the information the document contains. They will use pictures, get help or find a way to watch the process being performed. However, employees may ignore memos or all-company employee communication, relying on their managers to convey crucial information, or absorbing the information by watching changes in the workplace.

\section{The Literacy System}

As illustrated in Figure 1, study results show complex interactions between job task, literacy functions, individual literacy abilities, verbal interaction, and work process design. Job task analysis alone will miss major factors in work and learning. All of these interrelated factors come into play in understanding how employers can help workers succeed, and how teachers can prepare ESL workers for current and future jobs. Implications for employers and for ESL instructions are discussed in Chapter VII.

\section{STUDY LIMITATIONS}

The results of this study may have limited generalizability beyond the Tri-X workplace, because of study limitations discussed below. A broader-based study would be required to safely generalize results to other populations or workplaces in different industries. The limitations 
discussed below point out the challenges and sensitivities of conducting research in the workplace.

\section{Limitations of Research in the Workplace}

During this study, Tri- $X$ was undergoing wrenching change, including management turnover and extensive lay-offs. These changes created a workplace where people felt nervous and unsure of job stability. This fear extended to workers attending workplace ESL classes; in fact, many of these workers believed, with or without reason, that they were at greater risk of losing their jobs because of their limited English. Even though many of the participants were acquainted with and trusted the researcher, in this very sensitive environment, it was imperative that the study not increase participants' uncertainty, or put them at any risk whatever of becoming targets for lay-off. Administration of the B.E.S.T. test had to be discontinued because of participants' fear, however ungrounded, that poor test results would somehow get back to their management. It is clear that when administering any tests for research in the workplace, the entire environment must be taken into account, and adjustments to methods made along the way.

The shaky work environment also made it difficult for the researcher to "observe" participants' workplace in any systematic way, since participants were assured utmost confidentiality in their interviews; if the researcher, a corporate manager, appeared for any length of time in the workplace, participants might fear they were being "observed" for reports to their manager. Managers approached also believed that an "outside" observer in the workplace might disturb people. However, in 
the course of her regular job at the company, and in preparation for the study, the researcher had previously had ample opportunity to observe manufacturing worksites and talk to managers. In general, the selfreports of the participants concur with the researchers' previous observations; a group of ten managers to whom study results were presented also corroborated interview results. Self-report of English ability has been found to be a fairly reliable indicator of English ability in previous studies where tests have been used (Reder \& Cohn, 1984). Participants interviewed were very open in their discussions, and there is no reason to believe that uncertainties in the work environment make the interview data unreliable.

If other researchers intend to gather data in the workplace, experience with this study suggests that they should keep a number of factors in mind. First, they should be very familiar with the business context and organizational issues at hand during the study. Second, they must find ways to assure confidentiality of individual subject data, unless the subject has agreed to share the data with management and fully understands the implications of doing so. Third, in performing workplace task analyses or other observations, it should be made very clear to the workers the reasons for the presence of the researcher; results should also be shared with the participants if possible. The most unobtrusive way to conduct a true ethnographic study would likely be to take a job in the workplace and become a member of the work team.

The Fluctuating Adult Education Class. Original study plans called for interviewing every one of the students enrolled in Workplace ESL over the course of a year. Attendance in adult education classes is 
often erratic, due to family and work demands placed on the students. Although the researcher scheduled at least ten different interview times, some students had dropped out of class. Some students who were present on the day the B.E.S.T. test was administered (before discontinued) could not be tracked down later for an interview. In addition, a few students in the class were laid off during the study period. Because of the small number of subjects in this study, further research is needed to generalize results. 


\section{CHAPTER VII}

\section{RECOMMENDATIONS}

\section{RECOMMENDATIONS FOR EMPLOYERS}

Rothwell and Brandenburg (1989) note that employers use several approaches for making sure limited readers perform work successfully. Most commonly, they choose to screen out non-literate applicants, provide training programs, or redesign work processes or the literacy expectations of job tasks. This study suggests that employers may want to consider those approaches, but they should also consider how process design, teamwork, individual skills, and literacy functions interrelate. Employers should also build on the strategies limited readers already bring to the workplace, especially helping networks.

To rely on screening, ESL training, or job redesign alone is unlikely to yield optimum work results, or to increase the individual skill levels of ESL workers greatly. If the goal of testing screening is to determine whether a worker can perform the job, literacy testing alone may not reflect the real capabilities of the worker within the work system. Clearly, individual literacy skill is one more tool workers have at their disposal to perform the job, but other skills such as verbal communication skills, memory, and knowledge of the production process also contribute. 


\section{Work Process Design}

Work flow design can take advantage of existing helping networks and reading strategies. For example, placing a person with limited English proficiency in close physical proximity to someone who can demonstrate the process or help with reading could minimize learning time and "help" time. Asking manufacturing process engineers to collaborate with production workers to design procedures is likely to cut down on reading problems, at the same time that it minimizes redesign by taking advantage of the expertise of the people who perform the manufacturing process every day--the production workers. When mapping or documenting work processes in order to analyze them for improved efficiency, employers may also want to consider mapping the learning process, which may suggest training or work design process improvements.

\section{Process Documentation}

To the extent written process documentation is required on the job, documentation writers should consider the reading strategies of their production workers. People scan for important information, especially changes. Writers can help them by keeping format consistent, and signaling changes to the reader by highlighting changes or summarizing them at the beginning of the document. For limited readers and others, documentation should include as many visual aids such as tables, graphs, and illustrations as possible.

Employers should be aware that neither readers nor non-readers use documentation all the time. They rely on memory, on questioning 
each other, and on mutual problem solving as well. It is essential that employers not regard workers who use alternative strategies to accomplish literacy tasks as "sneaky" or devious. Rather, employers can benefit by looking at these alternative strategies as added tools in employees' skill kits. For example, the ability to build and sustain literacy helping networks requires strong relationship skills that can contribute to the success of the entire workgroup.

\section{Job Training}

This study suggests that hands-on job training is preferred by many employees over reading to learn. It also suggests that less proficient readers will be able to read training documents better once they have seen and practiced the procedure described. Employers should consider English comprehension and verbal skills in job training. Those ESL employees with very limited verbal skills combined with limited English reading skills may require hands-on guidance, or bilingual help.

\section{Supporting ESL and Literacy Training}

As discussed in Chapter I, many employers already offer ESL or literacy training in the workplace. This study has shown that limited readers and writers are often able to accomplish literacy tasks far above their individual skill level. Should employers sponsor literacy training?

Although ESL workers in this study are able to accomplish literacy functions in the workplace, those with greater reading and writing proficiency have more options available to them to solve work problems, and more ways to learn the job. Anything employers can do to encourage 
increased individual skills is likely to increase employee promotability and flexibility. Employers should not expect that literacy or ESL training alone will solve all workplace issues with limited readers. They must look at cultural issues, work design, documentation design and group relationships as well.

The interview results suggest that ESL workers do not use the job as a learning laboratory to increase their English skills as much as might be expected. Many production jobs examined in this study require little verbal interaction and English practice, and very few require writing beyond the level of short notes or filling in forms. Often, workers perceive a risk in revealing their inability to read or write. Classroom instruction provides a safe place for taking language risks and learning, as well as a chance to practice and attain skills higher than those required on the job.

Employers may want to consider the motivation of workers who attend ESL class. Students do not always want to talk about work, or relearn work vocabulary they already understand. Often, they are motivated by the desire to expand their horizons and increase their job opportunities. These motivations are likely to make them more valuable employees. Employers considering ESL training should recognize that they may not see dramatic changes overnight. Basic skills training is a long term investment. Short term solutions can be found in such process, workplace, and document redesign as those discussed above. 


\section{Employee Communications}

An employee communications survey conducted by the researcher at Tri-X at the same time the present study was being conducted showed that employees' top five preferred sources of information about the company are their manager, Tri-X Weekly News, electronic mail, employee meetings, and senior manager meetings--in other words, a mix of verbal and written sources.

Many organizations use print media, such as memos and newsletters, to communicate news about organization strategy, operations, events, and benefits. Very often, organizations assume that all employees read these communications, and employees are expected to comply with policies or expectations set forth in these communications. Communications such as employee newspapers are often used to create a feeling of community and teamwork; anyone who doesn't know the news becomes in a sense a marginal member of the work society.

Print Media Considerations. Companies depending on print media to communicate important information to a worker population that includes substantial numbers of ESL workers should consider the needs of limited English readers. First, companies should work with managers to assure that any information that is critical for business or legal reasons be conveyed to employees verbally, or that managers alert employees to the fact that certain documents are critical so that employees can be sure to get the help they need. An approach to consider is printing a short notice on the envelope or beginning of the documentation in each of the major languages in the company alerting employees that they should get help reading the document, or have their 
manager explain it to them. Managers may want to appoint partners for limited readers to help them with employee communication; this may be especially important for new employees who have not yet built up their own helping networks. Second, companies should review print communication, especially culture building communication such as newsletters, for readability, using clear concise writing supplemented by pictures and graphics. Documents written at grade levels higher than grade ten are likely to be unread by ESL readers with less than a high school education as well as many native English speakers with limited reading proficiency.

New Technology Considerations. More and more companies throughout the country are making use of electronic communication such as E-mail to ease the flow of information across increasingly complex and far-flung organizations. Very little research has been done on the social effects of moving to E-Mail, or the literacy requirements needed to participate fully in a company culture dependent on E-Mail for building relationships in other worksites or getting work done. If limited readers are expected to use these systems, they must be considered in the system design. However, work design that depends on E-Mail messages may increase the literacy demands on production workers who now write very little on the job.

RECOMMENDATIONS FOR WORKPLACE ESL INSTRUCTION

The Place of Job Task Analysis and Functional-Context Curricula

As discussed in Chapter II, job task analysis is a currently recommended, often officially mandated, approach to designing 
workplace ESL instruction. Job task analysis yields a functional-context curriculum, which uses workplace subjects, vocabulary, and materials to teach literacy or English. Instructors also frequently build less elaborate functional-context curricula simply by including some workplace materials in the classroom, and considering the stated needs of the employers. Both approaches assume that effective workplace programs must in some way simulate the workplace, and both have as their goal improved student performance in the workplace.

What should be the place of job task analysis, and of functionalcontext curricula in workplace ESL programs? The research discussed in Chapter II seems to show a direct relationship between the ability to transfer classroom learning to the job and the use of real or related materials and subject matter to teach literacy. Should the many studies linking job-related materials and learning be disregarded?

The results of this study suggest that building a program that recreates the workplace task-for-task may not provide value for the time spent creating it. This study indicates that workers already know how to do their jobs, and in fact quickly become acquainted with the technical vocabulary that is the focus of many workplace programs. It also suggests that individuals not only apply their own individual reading skills to accomplishing literacy functions, but also get the job done with the help of others and the help of strategies that do not require reading such as watching, listening, and using samples and pictures. Job task analysis is extremely time consuming; focusing on every discrete literacy task of each individual or separate job may yield lists of words and clues about which type of reading is used, such as reading to learn or reading 
to do. It does very little, however, to consider or build on help networks or alternative reading strategies.

Because the technique evolved from settings dominated by native English speakers, job task analysis does little to consider the interaction between English verbal skills and literacy. If the employer's or teacher's goal in using job-task analysis or functional-context curricula is solely to improve work performance through improving literacy skills, curriculum development resources might better be spent to redesign work processes, enhance hands-on job training, and increase verbal skills needed to navigate relationships and difficulties at work. If the goals of workplace ESL or literacy instruction are to expand "basic skills" in preparation for anticipated increased literacy demands or job promotion, the job task analysis becomes even more problematic. Job task analysis does very little to consider the needs or wishes of students to learn English for job promotion, career advancement, preparation for the increasing demands of the current job, or students' stated need simply to "read better."

Does this mean that ESL instructors should abandon the notion of functional-context curricula, or discontinue using workplace materials in class? Probably not, since few studies contradict the strong evidence showing that using workplace materials enhances transfer of training. Besides, employers may be more apt to fund programs that reflect workplace demands. However, teachers should take a wider view, using the strong points of a functional-context approach, and expanding from there. Perhaps the major strength in job task analysis is the exacting research required of the instructor in the workplace before developing a curriculum, and the knowledge she then brings to the classroom. A 
teacher who completes a job task analysis is likely to have a much better knowledge of the literacy challenges of the workplace and needs of the employer than a teacher who has never set foot in the place of work. Most likely, an instructor can gain sufficient knowledge of workplace issues and literacy applications through solid interviews with workers and managers, and observations. Observations should extend beyond the narrow task assigned to a student's job; they must include the work flow and the work process, and consider verbal demands as well as literacy demands; they must find and build upon strategies students are already using to succeed.

\section{Balancing Student and Employer Needs}

ESL instructors must balance the needs of the employer with the needs of the student. If students' main motivation for learning English or increasing literacy is to obtain a job promotion, read to their children or start their own business, they are unlikely to be motivated by classes that mimic experiences in their current jobs. These students may be very happy, and do well, with a general or basic skills program that increases overall English and literacy skills. Using workplace subjects or materials as one part of a broader curriculum could address employers' concerns as well as students' needs to expand.

If students' primary reason for attending class is to learn reading or writing in order to improve job current performance or job satisfaction, instructors should understand the workplace well enough to provide them with a battery of strategies for reaching the performance improvement goal as well as the literacy improvement goal. 
This study suggests that teachers can also play an important role in educating their beginning readers and writers about literacy. Recall that many participants in this study equated their English problems with "spelling." Teachers have a role in educating students about the interrelationships of speaking, reading, and writing English; as students progress, they should also help expand students' notion of reading and writing from mere decoding to a broader notion of reading and writing for meaning.

\section{Hands-On Classroom Approach Suggested by Study Findings}

Some participants in this study say that they can actually read better once they have seen a process demonstrated. They also say that they commit much work process to memory, but use reading and writing as ways to refresh their memories of processes they have observed. These participant comments suggest a "hands on" classroom approach for beginning readers in programs whose specific purpose may be to improve literacy and current job performance. Rather than patronize adult learners by bringing in literacy materials that tell them how to do a job they already know, teachers might bring in "objects" from the job such as familiar parts, products and so on, and have students actually create or improve on work processes and documents in class, using a kind of Language Experience Approach that builds from and reinforces job knowledge. Many managers who heard the results of this study remarked that their ESL workers often have excellent ideas about improving workplace processes but lack the verbal skills to share them, or writing skills to document them. An English classroom that builds 
literacy skills while improving the ability of the individual to contribute to process improvement or teamwork is likely not only to increase that person's current job performance, but also to increase their chances of being promoted or cross-trained.

\section{Rethinking the Role of the Workplace ESL Instructor}

Instructors in the workplace may improve the results of their classes (and expand career opportunities) by applying their training and knowledge to serve as what Robinson (1992) calls "performance consultants." Employers are predisposed to regard classroom training as an answer to all performance problems, when in fact those problems may be more systemic. The ESL instructor/ performance consultant could work with employers who have large ESL populations to help them discover the real reasons for poor performance, and explore a wealth of solution options. For example, an instructor might assist in redesigning work processes to promote teamwork or improve access to reading helpers, or work to improve intercultural communication problems that may masquerade as English problems. Just as their students use multiple strategies to solve literacy problems, teachers and employers can begin to look beyond the classroom to help students reach their goals.

\section{AFTERWORD: RUSSELL REVISITED}

At the beginning of this study, I introduced Russell, a not-sofictional manager trying to solve performance problems among some of his new ESL workers. Russell and nine other managers heard the 
results of this study, incorporated their experience, and decided to make some changes in order to solve the performance problems and keep valuable workers. First, one worker with very limited English verbal skills will receive ESL tutoring; others will be encouraged but not required to attend the Workplace ESL class. Second, new workers will be teamed up with a "buddy" to help train them and help navigate the new work relationships and processes. Third, documentation writers will design process documentation so that it clearly points out changes, and will attend a workshop on writing for lower-level readers. Fourth, the plant is considering beginning every new process design with a collaborative team that includes design engineers as well as workers who produce the products. 


\section{REFERENCES}

Basic English Skills Test. (1984). Washington, D.C.: Center for Applied Linguistics.

Business Council for Effective Literacy: A newsletter for the business community. (1988). Vol. 17.

Business Council for Effective Literacy: A newsletter for the business community. (1989). Vols. $18 \& 20$.

Business Council for Effective Literacy: A newsletter for the business community. (1990). Vols. $23 \& 24$.

Business Council for Effective Literacy: A newsletter for the business community. (1991). Vols. 26, $27 \& 28$.

Carnevale, A., Gainer, L. \& Meltzer, A. (1990). Workplace basics: the essential skills employers want. San Francisco: Jossey-Bass.

Crismore, A. \& Mikulecky, L. (1987). Investigating a process model of literacy in the workplace. Paper presented at the 32nd Annual Meeting of the International Reading Association, Anaheim, CA. (ERIC Document Reproduction Service No. ED 282 189).

Diehl, W. \& Mikulecky, L. (1980). The nature of reading at work. Journal of Reading, 24(3), 221- 227.

Dubin, F. (1989). Situating literacy within the traditions of communicative competence. Journal of Applied Linguistics, 10(2), 171-181.

Fields, E., Hull, W., \& Sechler, J. (1987). Adult literacy: Industry-based training programs. (Research and Development Series No. 265C). Columbus, Ohio: The National Center for Research in Vocational Education.

Fingeret, A. (1990). Changing literacy instruction: moving beyond the status quo. In Chisman and Associates (Eds.), Leadership for Literacy: The Agenda for the 1990s (pp. 25-49). San Francisco: Jossey-Bass. 
Fingeret, A. 1983. Social network: a new perspective on independence in illiterate adults. Adult Education Quarterly, 33(3), 133-146.

Fry, E. (1978). Fry readability scale. Providence, RI: Jamestown Publishers.

Gordon, E., Ponticell, J. \& Morgan, R. (1991). Closing the literacy gap in American business. New York: Quorum Books.

Gowan, S. (1990). "Eyes on a different prize": A critical ethnography of a workplace literacy program. Unpublished doctoral dissertation, Georgia State University, Atlanta.

Guthrie, J. (1983). Where reading is not reading. Journal of Reading, 26 (4), 382-384.

Harman, D. (1984). Functional illiteracy in the United States: Issues, experiences, and dilemmas. National Adult Literacy Project, a joint project of Far West Laboratory and the NETWORK, Inc. (ERIC Document Reproduction Service No. 259 232).

Heath, S. (1986). The functions and uses of literacy. In de Castell, A., Luke, A. \& Egan, K. (Eds.), Literacy, society and schooling: A reader. (pp. 15-26). Cambridge, England: Cambridge University Press.

Hull, G. (1991). Hearing other voices: A critical assessment of popular views on literacy and work. Berkeley, CA: National Center for Research in Vocational Education. (ERIC Document Reproduction Service No. 338 865).

Human capital: The decline of America's workforce. (1988, September 19). Business Week. (Special Report).

Johnston, W. B. \& Packer, A. B. Workforce 2000: Work and workers for the 21 st century. Indianapolis, IN: Hudson Institute.

Kazemek, F. 1985. An examination of the Adult Performance Level Project and its effects upon adult literacy education in the United States. Lifelong Learning, 9 (2), 24-28.

Keltner, A., Howard, L. \& Lee, F. (1981). English for adult competency. Edgewood Cliffs: Prentice Hall.

Kutner, M., Sherman, R., Webb, L., \& Fisher, C. (1991). A review of the National Workplace Literacy Program. Washington, D.C.: U.S. Department of Planning, Budget and Evaluation. 
Lee, C. (1989). The 3 R's. Training, 26(10), 67-76.

Levine, K. (1986). The social context of literacy. London: Routledge \& Kegan Paul.

Newman, A. \& Beverstock, C. (1990). Adult literacy. Newark, Delaware: International Reading Association, Inc.

Northcutt, N. (1975). Adult functional competency: A summary of performance requirements. Adult Performance Level Project. Austin: University of Texas.

Omega Group, Inc. (1989). Literacy in the workplace: An executive perspective. Bryn Mawr, PA.

Patterson, M. (1989). Workplace literacy: A review of the literature. Fredicton, New Brunswick: Department of Advanced Education and Training. (ERIC Document Reproduction Service No. 314 142).

Philippi, J. (1988). Matching literacy to job training: Some applications from military programs. Journal of Reading, 31(7), 658-665.

Qualtrough, S. \& Schamisso, A. (1989, September). What happens when US workers can't read. American Machinist, pp. 84-89.

Reder, S. (1987). Comparative aspects of functional literacy development: Three ethnic communities. In D. Wagner (Ed.), The future of literacy in a changing world, Vol. 1 (pp. 250-270). Oxford, England: Pergamon Press.

Reder, S. \& Cohn, M. (1984). A study of the extent and effect of English language training for refugees. Phase II: Classroom observation and community survey. Portland, OR: Northwest Regional Education Laboratory. (ERIC Document Reproduction Service No. 258 474).

Robinson, J. (1992). Performance consulting: Linking training to business needs. Pittsburg, PA: Partners in Change, Inc. Workshop presented to Tektronix, Inc.

Rothwell, W. \& Brandenberg, D. (1989). Solutions to basic skills deficiencies: Report of a survey. Unpublished manuscript.

Rothwell, W. \& Brandenburg, D. (1990). The workplace literacy primer. Amherst, MA: Human Resources Development Press. 
Rummler, G. \& Brache, A. (1990). Improving Performance: How to manage the white spaces on the organization chart. San Francisco: Josey-Bass.

Rush, T., Moe, A., \& R. Storlie. (1986). Occupational literacy education. Newark, Delaware: The International Reading Association.

U.S. Department of Labor \& U.S. Department of Education. 1988. The bottom line: Basic skills in the workplace. Washington, D.C.: U.S. Government Printing Office.

Sticht, T. (1981). Basic skills in defense. Alexandria, VA: Human Resources Research Organization.

Taber, S. (1987). Current definitions of literacy. Journal of Reading. 30(5). 458-460.

Zalman, R. 1989. Paradigms for literacy and learning: An inquiry into the design of workplace employee basic skills programs. Unpublished Master's Thesis. Massachusetts Institute of Technology, Cambridge, Massachusetts.

Zalman, R. (1991, February). The "basics" of in-house skills training. HR Magazine.

Zemke, R. 1989. Workplace illiteracy: shall we overcome? Training, 26. . 33-39. 
APPENDIX A

CONSENT FORM 


\section{INFORMED CONSENT}

$\mathrm{I}$, , agree to be a subject in the research

project on Resources for Literacy in the Workplace supervised by Mary Cohn.

I understand that I will be interviewed and tape recorded. I understand that I will also take an oral test and reading test.

I understand that this study may involve taking some of my English class time, and that I might think the interview asks some questions I might feel embarrassed about.

It has been explained to me that the purpose of this study is to learn more about how ESL workers use reading and writing.

I may not receive any direct benefit from this study, but my participation may help to increase knowledge that will help others in the future. Mary Cohn has offered to answer any questions I have about the study and what is expected to me, and explained any words in this agreement I do not understand. I have been assured that all the information I give will be kept confidential, and that the identity (names) of all the participants will remain anonymous. No one except the researcher will know my name as a participant. 
I understand that I am free to stop participating in this study at any time without danger to my participation in the English in the Workplace class or my employment.

I have read and understand the above information and agree to participate in this study.

Date:

Signature:

If you have problems that are a result of your participation in this study, please contact the Chair of the Human Subjects Research Review Committee, Office of Grants and Contracts, 345 Cramer Hall, Portland State University, (503) 725-3417. 
APPENDIX B

INTERVIEW GUIDE 


\section{INTERVIEW GUIDE}

1. All information in this interview is confidential.

2. Demographic Data:

- Native Country

- Number of Years in U.S.

- Number of Years Education in Native Country

- Number of months or years formal ESL training

- Can you read any other language besides English?

3. Please describe your current job: what you do every day at work. Who depends on your work? Do you do the whole process or are you one step in the process? Who is before or after you in the process? (i.e. next person in line, boss, etc.)

4. How many people do you work with? How often do you talk with them? What do you talk about together?

5. Are there other people in your work group that speak your native language? Do you talk to them at work? What about?

6. What things do you have to read or write in your job? How well can you do your job without reading anything at all?

7. Do you read the same types of things over and over, or different kinds of things every day?

8. Do you ever ask anyone to help you read or write something? Who? Does anyone ever ask you to help them read something? What do they ask you to help them with? Do you usually ask the same person for help? What do you do to help them in return?

9. When there is a new work process, or a new job to do, how do you learn how to do it?

10. How do you feel about reading and writing at work? What one thing would you like to be able to read that you can't read now?

11. Do you read or write at home? What? In English? In what language? 
APPENDIX C

SAMPLE TRANSCRIPT 


\section{"FATIMA"}

Iranian, Female, Age 50

Key:

$I=$ Interviewer

$\mathrm{F}=$ "Fatima"

(UI) = tape unintelligible

$(\mathrm{sp} ?)=$ spelling guess

I: Fatima, how long have you been in the United States?

F: Been here 13 years. April 11, 1979.

I: You came here in 1979?

F: After the revolution.

I: Did you go to school in Iran? How many years?

F: Yeah. I had a high school degree in Iran and I had three years uh special education training for teacher- eachers.

I: So were you a teacher?

F: About 18 years.

I: What did you teach?

F: I teach--beginning from first grade until sixth grade and uh I teach everything including the math writing reading history geography uh what again religion all those things.

I: So all the elementary school things?

F: Yes yes. Some teacher accepted to teach everything, some not. Some people don't wanna teach like uh math. They like to reading writing something like that. I enjoy to, I able to do, I work mostly boys and girls. Some teacher ignore to being with boys. Too hard to control or something. I worked with boys and girls.

I: Do you speak any other languages? 
F: My na--what--native language is Farsi. I can speak Turkish. I know little bit German language--not too much--because I was in Germany about once years. I learn over there but because I learn without studying they come easy they go easy. Not practicing that's why. But when I go someplace they speaking and using everyday learn and use.

I: But you don't read and write German--just speak.

F: Yes. No writing.

I: Do you read and write Turkish?

F: Yes. Write and read. But that Turkish is not that Turkish--you think about the Turkish country. We have two Turkey language. One is to Azerbaijian between Russia and Iran, that part--they have talking Turkey there. They speak Turkey. I know that one. The other Turkish is different. And also they changed alphabet as eh Latin. They try in Iran also change alphabet to Latin but people don't accept it there. (UI)

I: How long have you studied ESL?

F: Not much. I think I--before I one month, something like that, I dunno, one month. Altogether maybe three months.

I: Did you study English in Iran at all?

F: No. No. My first language in high school--second language was French. And you know that. (UI) we had choice to learn English or French second language. If I select English much much better was for me but I never had somebody me, teach me and that's my father would speak French.

I: OhI see.

F: Yeh that's why I go select French.

I: Can you speak French?

F: Oooh, no! (UI)

I: Can you tell me about your job, what you do every day?

F: Yes. (UI) I'm at Tri-X from 1981. I got hired and before it was six months temporary and then I got hired permanent. I was in XXX Road before about seven years something and then I got laid off and 
then I applied Bldg YYY and I got a job over there. Now I'm working about three years Division B.

I: Do you like it?

F: Oh, yeh. I like crazy. Crazy about working. I like job this kind of challenge nice. It's different.

I: Can you tell me what you do? Can you explain it to me?

F: OK. We have to--we working with different component. IC, diode, resistors, transistors, those kind of stuff but it's very small size. Very very small. Tiny. Cannot touch it. My first day I remember when I got Division B it was swing shift. They call, they become, those di-those component come in the box, waffle pack they call it, waffle pack. Have small tiny boxes on it. Each box have one dye. Really tiny dye.

(Fatima draws a picture)

It's not visible even some of 'em. And then I look number what number, on the top of the box they write in what number and that lady told me 'Get that number' I got my part number and then I opened waffle pack I said how come this is empty I put them in the garbage.

I: You put it in the garbage?

F: Yes. And I got another one. This is have nothing on it. Get another one. I got another one ya know. Open up--at this time light goes on. (UI) kinda shiny because light is--they make 'em kind a I don't what material it is--look like those kind of stones ya know. Expensive things. Glass kind of pieces.

I: Diamonds-- it s made from diamonds?

F: Look like diamonds. When light on top of that--shiny. My god it was (UI) I know I have to be very careful. (UI) because we use scope--we cannot see like that--microscope. And then those tiny parts have direction.

I: So you look under the micrscope?

F: If you put under the microscope and you adjust it, you can see oh my god it's another world. 
It's beautiful, shiny. Very interesting how they make it that thing. And they even direction in that. You have to be careful put find the direction, follow

I: Is it in writing?

F: No. There is kinda--there is kinda sign like uh right now I work look like each one I call name (UI) some finger here, some finger here. Look like a fish.

I: Comes with a drawing?

F: Right--have to put this way.

I: What do you do with the parts?

F: This parts goes on circuit. They call circuit, small substrate. We cannot call circuit board because circuit board is a big and we work another area circuit board. This is a hybrid circuit that's what they call it. And then we put (UI) they go different step different sequ-what do you call it--sequence. And first they go fat they make a line on it they print and they make it some design I dunno and come out to us--they go another step they screen print it they put epoxy on it. Then after come my area--that is my area I take 'em I follow procedure and part number and take all those part number and then now I'm working with Harkis (sp?). Name is Harkis is a kind a person name. Harkis (UI). Big huge machine that has a camera inside--computer. Those parts and all those things is computerized the machine and we just punch some command in there. And the screen shows us direction.

I: So where do you get your work from? Who gives you your work? Do you get it from a bin or what? Who gives it to you?

F: Oh they have a schedule to--

I: You go pick it up?

F: Work come from fab. They call fab area they do screen print those things because big open area, different line, different manager have different group and they know like my group parts goes over there and screen print person come take a part and then screen printed and come back my area put in the shelf.

I: So a person comes and puts it in the shelf then you get it from the shelf. 
F: Yes. We know which part we have to do today or shipment this week. We follow procedure and we go find part.

I: So when you come in to work you have to read something?

F: Sure. On the board, like this board, my manager put dot his this this this first. Start this part first, finish this, we have ship, test this.

I: Does your manager also tell you or do you only read it?

F: No. Now we know how to follow those commands.

I: When you're finished with your work, where do you put it?

F: It goes another section, another sequence that call Loreal (sp?) Loreal also that's another machine. That diamond machine. And need more part goes on that circuit some other person put it on. After finish, they cure. They put it in the oven. They go in the oven and then they cure it. After cure they come out again go another section another lady take and they broke it piece by piece. Some circuit is four parts, some circuit is eight, some six something. They broke it single. They come array, they call array.

I: By hand?

F: Yeh. They have, they use finger card and then they broke it.

I: Do you do all different kinds of jobs or the same job all the time?

F: We trying on different job. I know how to test this area. I know howthis is my new job.

I: How long have you been doing this job?

F: Maybe six months. This is my new job I train on that. Loreal kind of this machine, but this is more sophisticated than Loreal.

I: How many people on your team.

F: Yeh we are, I think we are twenty of us. Twenty people working.

I: Do you talk with the people on the team?

F: If necessary, yeh.

I: What do you talk about? 
F: Work. Not much, they don't--

I: What kind of things?

F: Anything. (UI) problem. People have problem, life problem, work problem. We can talk about it but not pleasant for company because if, they don't want social at work. At work time because we (UI).

I: When you are talking about work things, what kind of things are you talking about?

F: If there's problem, why this part is wrong part, or you did wrong direction or what is too much epoxy or those kind of problems.

I: Problem solving?

F: Yeh. Then we associate together, we talk together and we solve (UI). We have also paper, worksheet. Like I did this sequence, I have to sign it, they go another person, if find any problem they call me, 'oh Fatima you did this job.'

I: So when you have a job you have a worksheet, you sign it? What's on the worksheet?

F: Worksheet show me which parts, I put it I used that part.

I: Is it mostly just numbers, or words?

F: There's number and there $Q$ number, means $Q C$ number come from company or whatever, company knows if something problem. Not always operator problem. Is part problem. Some this part have no good. They know which $\mathrm{QC}$ number is an then they follow that number find out what's wrong--engineer.

I: So you have to sign it so they can follow the part?

F: Right. Find out where is part. (UI)

I: What other things do you have to read at work?

F: Just machine uh (UI) punch numbers, command it give me. Computer--manual. But I don't have manual always by myself. When I learn I use manual. But now I doing myself I don't use it.

I: So you don't have to read? 
F: Yeh, I read. First uh first time you give manual I give manual (UI). But when I work with machine day by day and I open for me what is going on, what this say, what's this mean. Then more back to book.

I: Then you understand better after you've applied it a little bit?

F: Yes. You get more training, and then read again you understand more. Myself, I think. Everybody maybe because most not much good reading and writing (UI).

I: When you have a question about reading and writing or something that you read, who do you talk to?

F: Oh I am open. I'll call everybody. Anybody pass I call please engineer write this, I cannot write this. Because something unfinished. Do a job, it's unfinished. I have to finish. I have to write now I can't classroom. I did unfinished job over there I should explain second person come in, swing shift come in.

I: So you write a note?

F: Yeh. If some word I don't know dictation write or some I call please show me.

I: Do people help you?

F: Sure.

I: So what do you do in return for their help?

F: Thirteen years, 'thank you.' And my 13 years I never had problem ask questions someone. Only one time one lady when I ask question what is this--'I'm not your teacher!'

I: But most people are pretty nice?

F: Most people. Only one person.

I: Are you the only person in your group who's not American--or are there other people?

F: No, no we have from Philippine we have from Vietnam we have Mexicans. We have, what--

I: So you ask whoever you can for help? 
F: Yeh. Some Oriental they know, some not. Most I ask American friends. They know better I am sure they know. Or I have my dictionary with me. I have my dictionary and I look at that if I have any questions. But I no hesitate at work specially. At work no hesitate. I question any come around.

I: It sounds like at work you have to write notes--what else do you have to write?

F: Not much. Not much writing. But reading come up.

I: What kind of things do you have to read?

F: Reading is oh what's going on in the company--

I: What do you do when you get a memo? Do you understand the memos?

F: Generally. When I read uh all things I get some idea what's going on. Not all.

I: Then what do you do? Ask for help?

F: And then for sure manager explain what this is, what's going on. Or I can go home my husband explain. 'I have homework for you.' $\mathrm{He}$ read for me what going on. And Weekly News sometime.

I: Do you read Weekly News?

F: Yeh I like to read. Little tiny writing too much. But some parts. I like to know what's going on in the company. I don't understand I ask. Plus my husband at home--newspaper, I like to read--I like to have some book, not very kids stuff. Good things I can read it and understood.

I: You read at home?

F: No not really. Not even my language. I forgot my own language.

I: So you're looking for some books to read?

F: I like to book, not very tiny writing. Little bit bigger writing and interesting subject and I can understand my level.

I: Have you been able to find those books? 
F: No. I don't. There's too much science things or too much heavy it's not my level.

\section{I: Can you read the newspaper?}

F: Uh yesterday one of engineer find an article about Iranian lady (name) in the Oregonian and he cut for me. (UI) I read those and I understood he what he trying to understand. But not like you can read and understand. But what's going on I understand (UI) But some words I don't know.

I: When you have to learn something new at work, how do you like to learn it? Do you like to read, have somebody show you?

F: Usually I like to learn. I like to know different job and able to do all kind of job in the work. Most things I know how to do because they put on the training. And uh usually we have trainer. Especially this machine--Harkis machine, need trainer. I have engineer train me, yeh she sat behind me, beside me and she explain machine what is goin' on, if do this this happen and she explain everything for me and then I try to run machine. And run machine in XXX Road more complicated than this machine. We learn by looking and listening but she--sometime because she's engineer little bit, she's not trainer, she's engineer. Trainer is different. She use maybe professional way to explain is a little bit difficult I say, 'Oh please little bit more open'--and then she try for explain.

I: How do you feel about reading and writing at work? Is there anything else you'd like to tell me?

F: I don't have any problems so far. Just like even not write, even I wanna tell you something I know dictation is not right but you understand what I'm saying.

\section{I: On a note?}

F: Yes. It's "a" or "ed" you put this wrong but this is not this. 'OK, thank you, correct me.' An then the person the note have to write this way. I say thank you. I don't have that kind of problem. If something note very important I have to understood I go directly to manager and she explain for me but we don't have usually don't have those kind. 
APPENDIX D

FRY READABILITY SCALE GUIDELINES 


\section{FRY READABILITY SCALE GUIDELINES}

The following guidelines, which follow Fry's (1978) approach to measuring readability were used to conduct the Fry readability analyses in this study .

1. For each document analyzed, three passages of one hundred words are chosen at random by opening the document to random pages. Numbers or dates, such as "1986" or phone numbers are counted as one word. Abbreviations and acronyms are counted as one word.

2. For each passage of 100 words, the number of syllables are counted. Digits within a number are each counted as a separate syllable. For example, "1986" contains four syllables. Abbreviations and acronyms, such as U.S. or "CAD" (as in Computer Aided Design) are counted as one word, with each letter counted as one syllable. U.S. is counted as two syllables, CAD as three. Fry (1978) suggests that an alternate approach can be used, in which multisyllabic words such as proper names used several times in close proximity can be counted as one word. This approach is not applied in this study.

3. For each passage of 100 words, the number of sentences are counted. Fry's guidelines are vague on such configurations as headlines, topic heads, or sentence fragments displayed in lists. For this study, these sentence fragments are considered sentences.

4. For each document analyzed, the average number of syllables and sentences is calculated for the three passages chosen from the document by adding the total number of sentences in each passage, and dividing by three, and adding the total number of syllables in each passage, and dividing by three.

5. The Fry Readability Scale (1978) is a simple tool resembling a slide rule which displays a range of average syllables and average sentence numbers. The researcher lines up the average number of sentences and syllables found in the document. The tool applies Fry's algorithm for determining grade level readability, and displays the resulting grade level readability. 